Review

\title{
Mechanisms of the Shape Memory Effect in Polymeric Materials
}

\author{
Xuelian Wu ${ }^{1}$, Wei Min Huang ${ }^{2, *}$, Yong Zhao ${ }^{2}$, Zheng Ding ${ }^{2}$, Cheng Tang ${ }^{2}$ and Jiliang Zhang ${ }^{2}$ \\ 1 School of Mechanical Engineering, Jiangsu University, 301 Xuefu Road, Zhenjiang 212013, China; \\ E-Mail: xlwu@ujs.edu.cn \\ 2 School of Mechanical and Aerospace Engineering, Nanyang Technological University, \\ 50 Nanyang Avenue, 639798, Singapore; E-Mails: zhao0102@e.ntu.edu.sg (Y.Z.); \\ ding0035@e.ntu.edu.sg (Z.D.); tang0218@e.ntu.edu.sg(C.T.); m110056@e.ntu.edu.sg (J.Z.) \\ * Author to whom correspondence should be addressed; E-Mail: mwmhuang@ntu.edu.sg; \\ Tel.: +65-6790-4859; Fax: +65-6792-4062.
}

Received: 19 August 2013; in revised form: 18 September 2013 / Accepted: 23 September 2013 / Published: 30 September 2013

\begin{abstract}
This review paper summarizes the recent research progress in the underlying mechanisms behind the shape memory effect (SME) and some newly discovered shape memory phenomena in polymeric materials. It is revealed that most polymeric materials, if not all, intrinsically have the thermo/chemo-responsive SME. It is demonstrated that a good understanding of the fundamentals behind various types of shape memory phenomena in polymeric materials is not only useful in design/synthesis of new polymeric shape memory materials (SMMs) with tailored performance, but also helpful in optimization of the existing ones, and thus remarkably widens the application field of polymeric SMMs.
\end{abstract}

Keywords: shape memory effect; mechanism; polymeric material; thermo-responsive; chemo-responsive; optimization; design

\section{Introduction}

Traditionally, the shape memory effect (SME) refers to the following interesting phenomenon, i.e., after being severely and quasi-plastically distorted, a material is able to recover its original shape at the presence of the right stimulus [1-3]. Figure 1 reveals the SME in three commonly used engineering polymers, namely, polytetrafluoroethylene (PFTE), polylactide (PLA) and ethylene-vinyl acetate (EVA). 
Figure 1. Thermally induced SME in PTFE (I), PLA (II) and EVA (III). (II and III: reproduced with permission from [3]. Copyright 2012 Springer). (I) PTFE: (a) original shape; (b) after stretching at room temperature; and (c-d) after gradually heating to $340{ }^{\circ} \mathrm{C}$ in two steps (above the glass transition temperature and at the melting temperature). (II) PLA: (a) original shape; (b) after expansion at high temperatures; and (c) after heating for shape recovery. (III) EVA: (a) original star shape; (b) after expansion into circular shape at high temperatures; and (c) after heating for shape recovery.

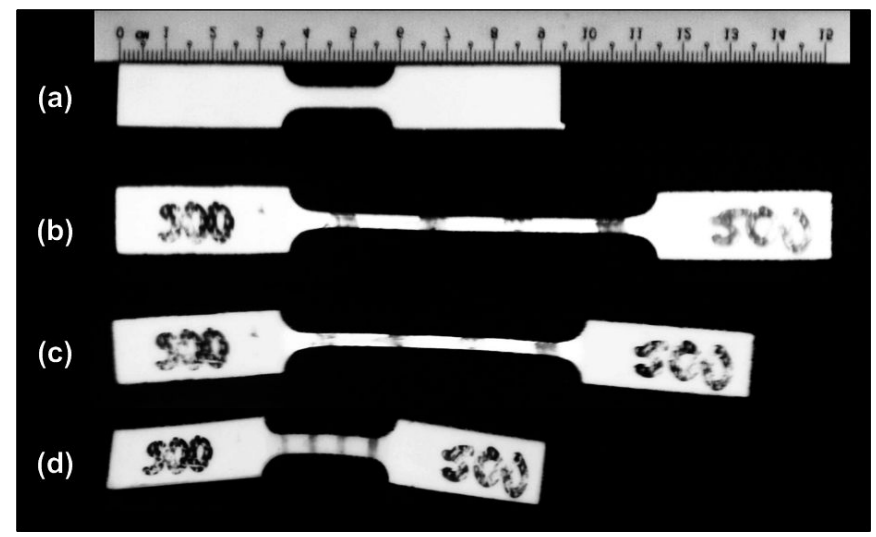

(I)

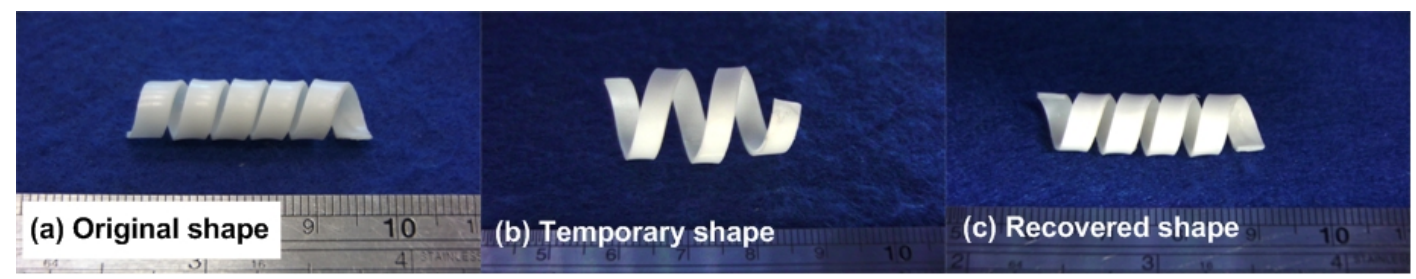

(II)

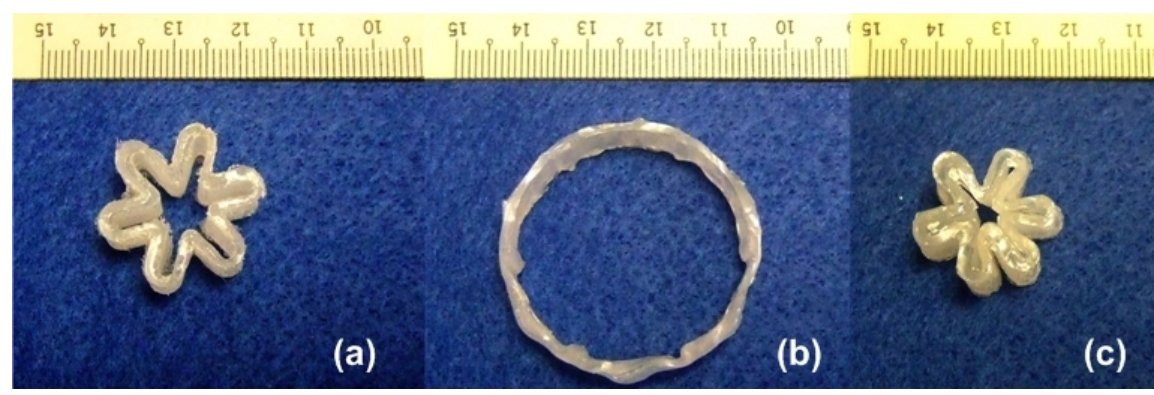

(III)

The SME is fundamentally different from another commonly observed phenomenon, namely, the shape change effect (SCE), in which a material returns its original shape either instantly or gradually when the applied stimulus is removed [4,5]. A typical example of the SCE is reversible elastic distortion when a piece of material is elastically distorted. Note that upon unloading, shape recovery might be either instantly or in the case of a viscous-elastic material, gradually in the SCE.

From an energy point of view, the difference between the SME and SCE is due to the magnitude of energy barrier between two states (marked as A and B in Figure 2), in which one is with, while the other is without, the presence of the right stimulus [3]. As illustrated in Figure 2, in the case of high energy barrier $(H)$, additional driving force is required for shape recovery (i.e., the SME); while in the 
case of low energy barrier, the SCE can be realized either instantly or gradually (in the case of low energy barrier $H^{\prime}$ ).

Figure 2. Shape memory effect (SME) and shape change effect (SCE). (Reproduced with permission from [3]. Copyright 2012 Springer).

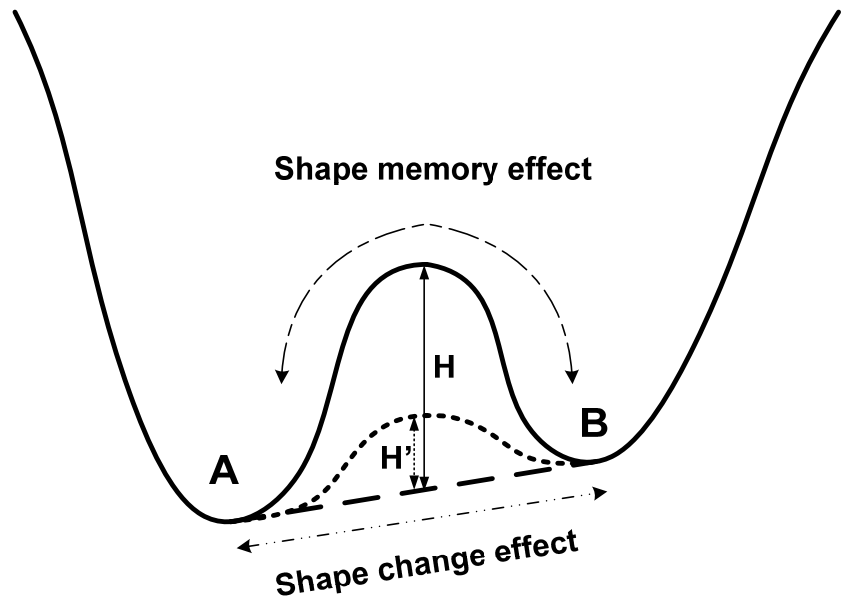

As pointed out in [3], the SCE and SME may coexist in one material, i.e., a material may behave and thus be classified either as a shape change material (SCM) or as a shape memory material (SMM), dependent on the exact working condition/environment. For instance, loading within the elastic range of a piece polymer at low temperatures, the material is SCM; while loading to beyond its elastic range, the quasi-plastic deformation may be recovered upon heating or immersing into a particular chemical (without any apparent temperature variation), so that the material is SMM.

Although the term SME originally referred to the shape memory phenomenon observed in an AuCd alloy in the 1930s, heat shrinkable polymer and water shrinkable polymer actually have a much longer history that began even well before the coining of the term SME [5-7].

Currently, the SME in polymeric materials can essentially be triggered by four basic types of stimuli, namely temperature variation (thermo-responsive, including both cooling and heating either directly or indirectly); chemicals (chemo-responsive, including water, ethanol and $\mathrm{pH}$ change etc.); light (photo-responsive, without apparent temperature fluctuation); and, mechanical force (mechano-responsive, including impact and pressure) [2-5,8-18].

In the past decade, extensive and continuous research efforts have been devoted to developing new polymers with the SME and/or improving the existing ones for higher performance [14,19-30]. On the other hand, a few new shape memory phenomena have been discovered [31-47], which not only enhance the flexibility of the current shape memory technology, but also add in new dimensions for extended versatility and adoptability. Consequently, a number of novel concepts have been proposed for a range of engineering applications [45,48-54], in particular in the field of biomedical engineering as of the last couple of years $[24,43,55-70]$.

The purpose of this paper is to present a brief review about the underlying working mechanisms for various commonly observed shape memory phenomena in polymers. A good understanding of the fundamentals behind various types of shape memory phenomena in polymers is not only useful in 
design/synthesis of new polymeric SMMs with tailored performance and optimization of the existing ones, but also very helpful for modeling and simulation of their stimulus-responsive behaviors.

The outline of this paper is as follows. Section 2 discusses the basic working mechanisms behind the classic SME. Section 3 extends the discussion from the basic shape memory phenomenon to other shape memory phenomena recently discovered. Based on the background knowledge presented in Sections 2 and 3, in Section 4, the design of new polymeric SMMs with required features and optimization of existing ones for tailored performance are presented. Some major conclusions are summarized in Section 5.

\section{Working Mechanisms}

There are many ways to achieve the SME in materials based on various working mechanisms. In Figure 3, a line-shaped indent is made on the top of an EVA-based melting glue droplet. After heating to above the melting temperature of the melting glue, the indent disappears and the droplet recovers its original shape. In this example, shape recovery is driven by surface tension when melting glue is heated to fully melt, which pulls the droplet surface back to the original spherical shape for energy minimization. As we can see, like many others, such a working mechanism is limited to some very special situations only.

Figure 3. Thermally induced shape recovery due to surface tension in an EVA-based melting glue droplet. (a) Original shape; (b) after indented for a line; and (c) after heating for shape recovery.

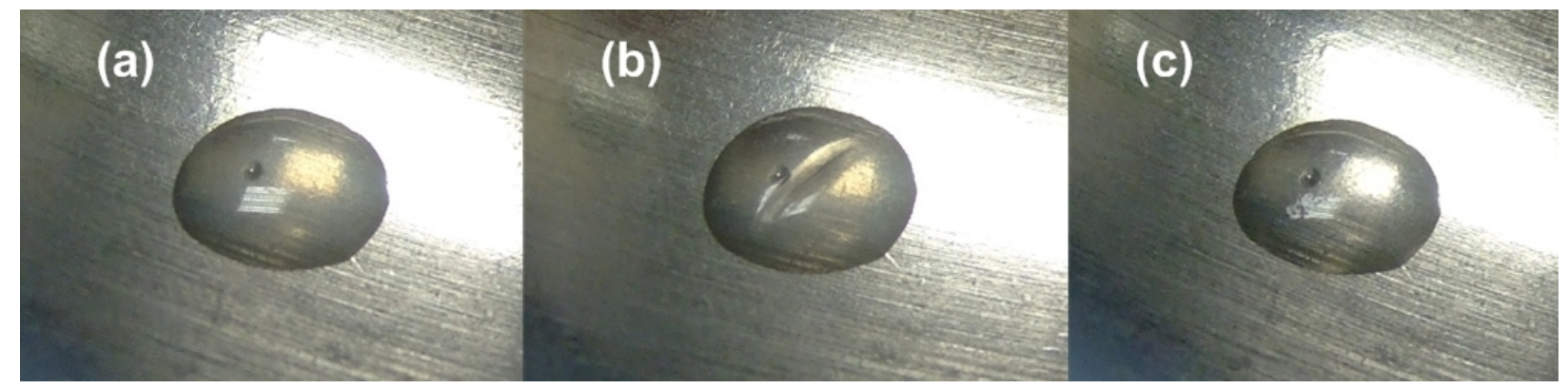

\subsection{Basic Working Mechanisms}

Instead of exhausting efforts to have a complete list of every possible working mechanism in all real engineering practice, in this review paper, we will focus on the generic ones, which are applicable for a wide range of polymeric materials and their composites.

In this section, we take heating-induced SME as an example to reveal possible working mechanisms which can be easily implemented in most of polymers, if not all, and their composites.

Different from their metallic counterpart, namely shape memory alloys (SMAs), in which the reversible martensitic transition either induced thermo-mechanically or thermo-magneto-mechanically, is the driven mechanism [1,6,71-73]. In a general sense, the SME in polymeric materials is fundamentally based on a dual-component system, in which one component (segment or domain) is always elastic within the temperature range of our interest (for the thermo-responsive SME), while the other component (segment or domain) is able to reversibly change its stiffness (and also easily deform in a plastic manner 
in the low stiffness state) depending on if the right stimulus (heat in the case of thermo-responsive SME) is presented $[2,4,10,49]$. The glass transition and melting are the two most commonly utilized transitions in polymers for the thermo-responsive SME.

A typical SME cycle for a heating-responsive SMM includes two parts, namely programming and shape recovery $[1,4,45,74,75]$. As illustrated in Figure 4, in the first step "a", a piece of SMM is strained to a maximum strain of $\varepsilon_{m}$ at high or low temperatures. Subsequently, with or without the step of cooling back to room temperature, the SMM is unloaded ("b"), and a residual strain of $\varepsilon_{u}$ is resulted at room temperature. Shape fixity ratio $\left(R_{\mathrm{f}}\right)$, which is normally defined as,

$$
R_{\mathrm{f}}=\frac{\varepsilon_{u}}{\varepsilon_{m}}
$$

is one of the key parameters in characterizing the shape memory phenomenon of a SMM. This ends the programming process.

Figure 4. Illustration of a typical SME cycle in heating-responsive SMM.

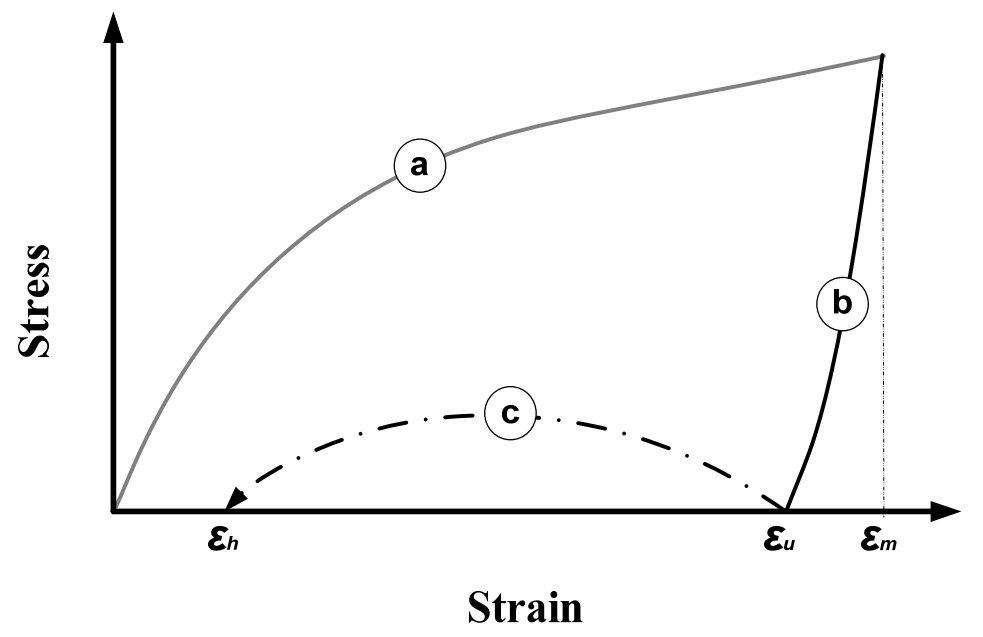

In the following shape recovery process, the material is heated ("c") and the final remaining strain is $\varepsilon_{h}$. Shape recovery ratio $\left(R_{\mathrm{r}}\right)$, which is normally defined as,

$$
R_{\mathrm{r}}=\frac{\varepsilon_{u}-\varepsilon_{h}}{\varepsilon_{u}}
$$

is another key parameter in the characterization of SMMs.

It should be pointed out that in some polymers, such as EVA, significant strain recovery may occur at low temperatures right after programming, largely due to the nature of high viscous-elasticity in these materials. Hereinafter, we ignore this effect and other minor factors, such as thermal expansion, in the discussion. Of course, time-related and rate-dependent effects, such as relaxation, creeping and strain rate effect, which are commonly observed in polymeric materials, can be included for a more precise investigation [76-86].

Regardless of the exact composite and synthesis method, according to [3], there are three basic working mechanisms for the heating-responsive SME in most - if not all —of the current polymeric materials: dual-state mechanism (DSM), dual-composite mechanism (DCM), and partial-transition mechanism (PTM). Refer to Figure 5 for schematic illustration of these three mechanisms. 
Figure 5. Basic working mechanisms for the heating-responsive SME in polymeric materials. (I) Dual-state mechanism (DSM); (II) dual-component mechanism (DCM); (III) partial-transition mechanism (PTM). (a) Original sample at low temperatures; (b) upon heating and compressing; (c) after cooling and constraint removal; and (d) after heating for shape recovery. (Modified from [3]).

(l)

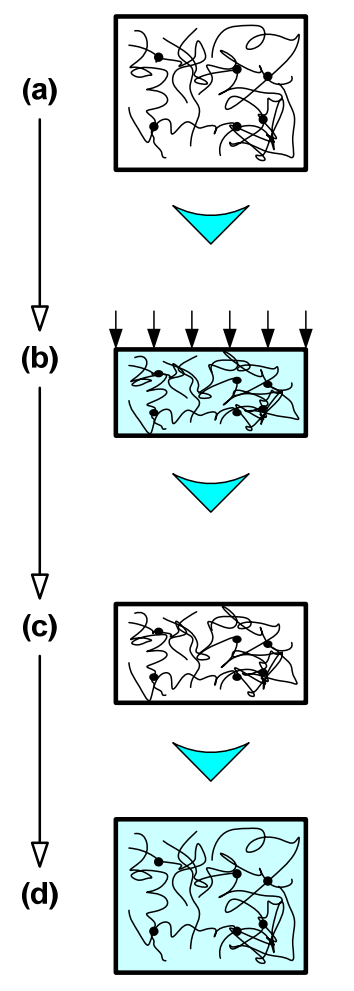

(II)
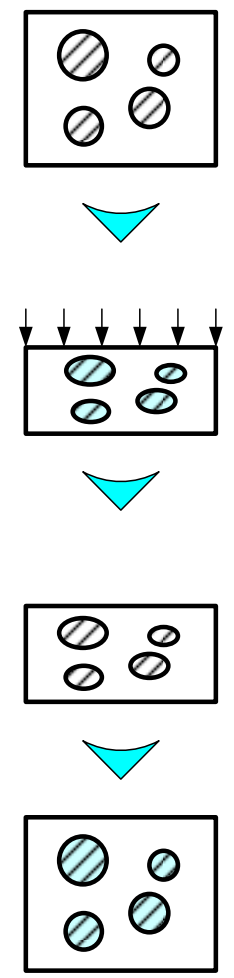

(III)

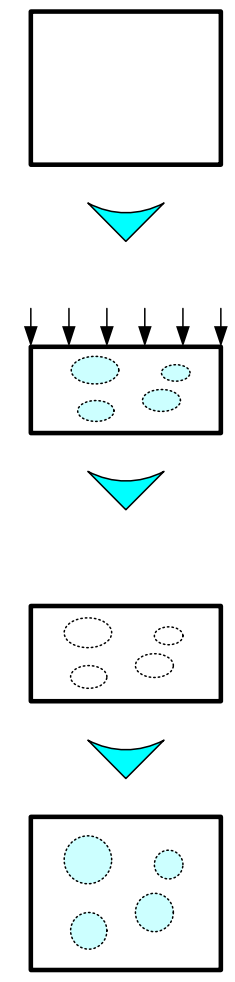

\subsubsection{Dual-State Mechanism (DSM) (Figure 5I)}

Silicone is a typical example under this mechanism for the heating-induced SME [3]. Since the glass transition temperature $\left(T_{\mathrm{g}}\right)$ of silicone is normally well below $0{ }^{\circ} \mathrm{C}$, at around room temperature, silicone is in the rubbery state and responds to external loading elastically in a rubber-like manner. If the distorted shape is maintained while cooling to below its glass transition range, since the micro-Brownian motion is frozen in the glass state, the distorted shape can be largely maintained even after the constraint is removed. Heating back to room temperature, silicone returns to its rubbery state and thus the micro-Brownian motion is reactivated, which drives silicone to recover its original shape.

Although most engineering polymers have their $T_{\mathrm{g}}$ above room temperature, so that they are in the glassy state, the aforementioned working mechanism for the thermally induced SME is still largely applicable.

Since the glass transition is a commonly observed phenomenon in most polymers, and therefore there are two states, namely the glassy state and rubbery state, in these polymers, heating-responsive SME may be considered as an intrinsic feature of almost all polymers and their composites. Good cross-linked net-points (including physical cross-linking, e.g., tangling, chemical cross-linking, and non-covalent interaction, etc.) are required to store elastic energy, which essentially provides the driving force for shape recovery [10]. 


\subsubsection{Dual-Component Mechanism (DCM) (Figure 5II)}

A lot of polymers, such as EVA and polyurethane (PU) $[3,19,45,75,87]$, have a hard/soft segment structure, while some polymers and polymer hybrids/blends have an inclusion-matrix microstructure [4,7,88-96]. If the hard segment or matrix is elastic within the temperature range of our interest, and the soft segment or inclusion is able to significantly alter its stiffness when being heated by means of either the glass transition or melting, we are able to realize the heating-responsive SME in these polymers.

For simplicity, we may call the elastic matrix/segment the elastic component, while the inclusion/soft segment is considered to be the transition component. After programming either at high or low temperatures, the elastic component stores elastic energy. On the other hand, the plastically distorted and (re-)hardened transition component provides constraint to prevent shape recovery at low temperatures. Only reheating to soften the transition component can remove the constraint and, thus driven by the stored elastic energy in the elastic component, the polymer returns to its original shape.

\subsubsection{Partial-Transition Mechanism (PTM) (Figure 5III)}

Instead of having a complete transition, heating may stop at a temperature within the transition range. As such, when deformed, the un-softened portion may serve as the elastic component to store elastic energy, while the softened portion may behave as the transition component. Following this mechanism, instead of utilizing surface tension as in Figure 3, the heating-responsive SME can be realized in melting glue by means of heating for partially melting [3].

It should be pointed out that in real practice, depending on the exact material, above three mechanisms may be utilized individually or in a combined fashion.

Although rather unconventional, cooling is indeed the other possible approach under the category of thermo-responsive SME. However, the transition component should be able to soften upon cooling, which is not a commonly accessible feature in nature for us to utilize. So far, cooling-responsive SME has only been demonstrated by means of using tin (based on the phenomenon of tin disease) and poloxamer 407 (P407) as the transition component [5,11]. Figure 6I shows that P407 melts upon cooling to $4{ }^{\circ} \mathrm{C}$ and Figure $6 \mathrm{II}$ reveals the cooling-responsive SME in an elastic spong-P407 hybrid.

Figure 6. Melting of P407 upon cooling (I) and the cooling-responsive SME in an elastic sponge-P407 hybrid (II). (Reproduced with permission from [11]. Copyright 2012 Elsevier).

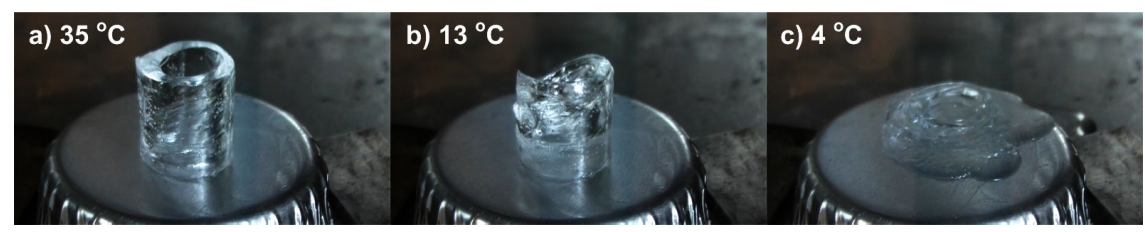

(I)

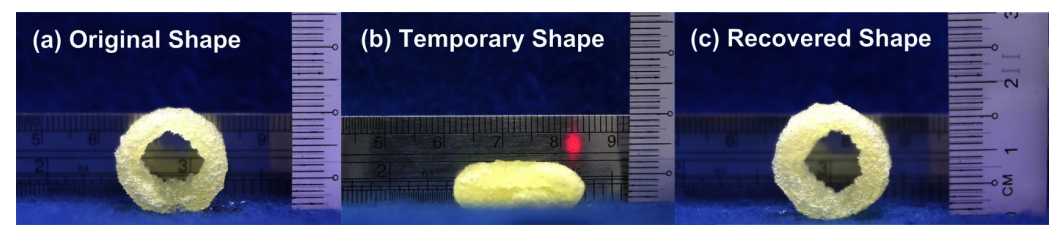

(II) 


\subsection{Other Types of Stimuli}

Other than temperature variation by means of either heating or cooling to soften the transition component, there are many other ways to release the stored elastic energy in the elastic component to drive the shape recovery.

The plasticizing effect is commonly observed in many polymers upon immersing into the right chemical. Since the plasticizing effect is able to effectively reduce the $T_{\mathrm{g}}$, instead of heating over $T_{\mathrm{g}}$ to trigger the thermally induced SME, to reduce the $T_{\mathrm{g}}$ of a polymer to below room temperature by means of exposing to the right chemical for the plasticizing effect is an alternative for shape recovery [14,97-100]. Such a chemo-responsive SME is generic and applicable to all three working mechanisms presented in Figure 5.

In real implementation, according to the magnitude of volume expansion in polymers, there are three categories under the chemo-responsive SME, namely softening, swelling and dissolving [3].

\subsubsection{Softening}

As shown in Figure 7, a piece of PU wire which is $1 \mathrm{~mm}$ in diameter and has an initial $T_{\mathrm{g}}$ of $35^{\circ} \mathrm{C}$ is pre-bent. After being immersed into room temperature water (about $22{ }^{\circ} \mathrm{C}$ ), it gradually returns its original shape. There is no apparent volume expansion at all and according to Figure 8 , in terms of weight percent, the absorbed water is less than $5 \%$.

Figure 7. Water-responsive SME (shape recovery of PU polyurethane in room temperature water). (Reproduced with permission from [101]. Copyright 2005 American Institute of Physics).

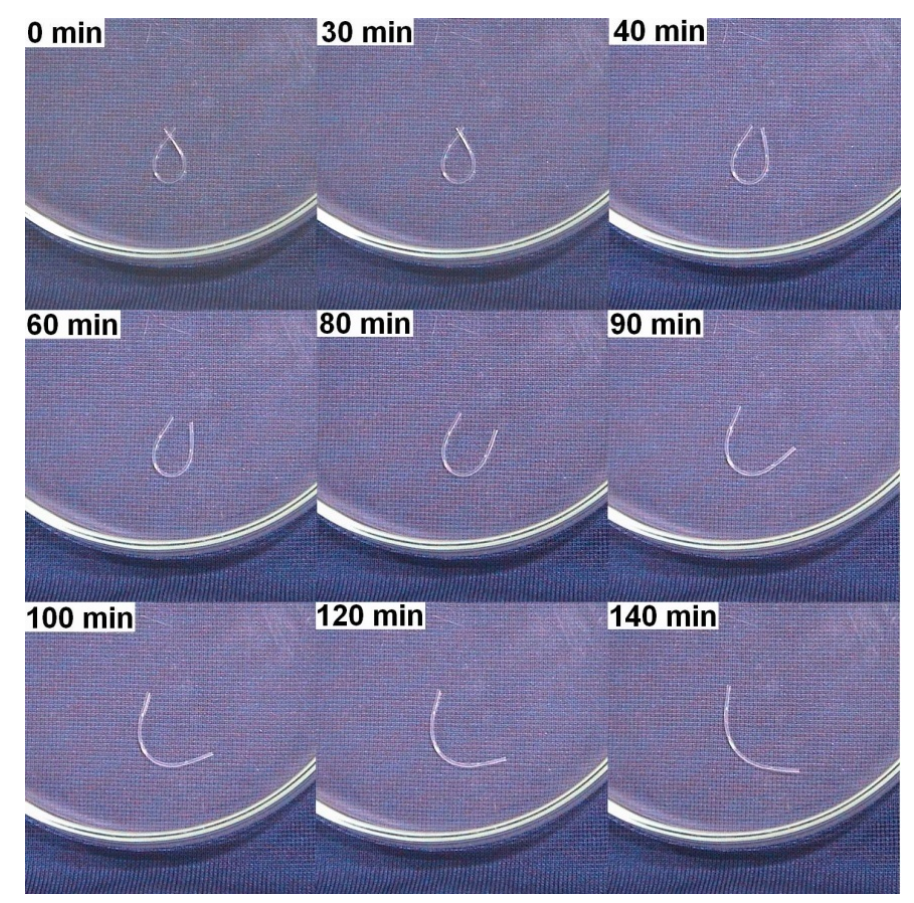

Furthermore, Figure 8 reveals that the absorbed water has two parts, one part is free water which does not have significant effect on the $T_{\mathrm{g}}$ and can be removed upon heating to less than $120^{\circ} \mathrm{C}$, while the other part is bound water, which can reduce the $T_{\mathrm{g}}$ remarkably (up to $30^{\circ} \mathrm{C}$ ) and can only be 
removed upon heating to above $120^{\circ} \mathrm{C}$ [20]. In addition to water, ethanol is another chemical which can trigger the chemo-responsive SME in PU, and in a much higher speed [102].

Figure 8. $T_{\mathrm{g}}$ versus ratio of water to shape memory polymer (SMP) in wt \%. (Reproduced with permission from [101]. Copyright 2005 American Institute of Physics).

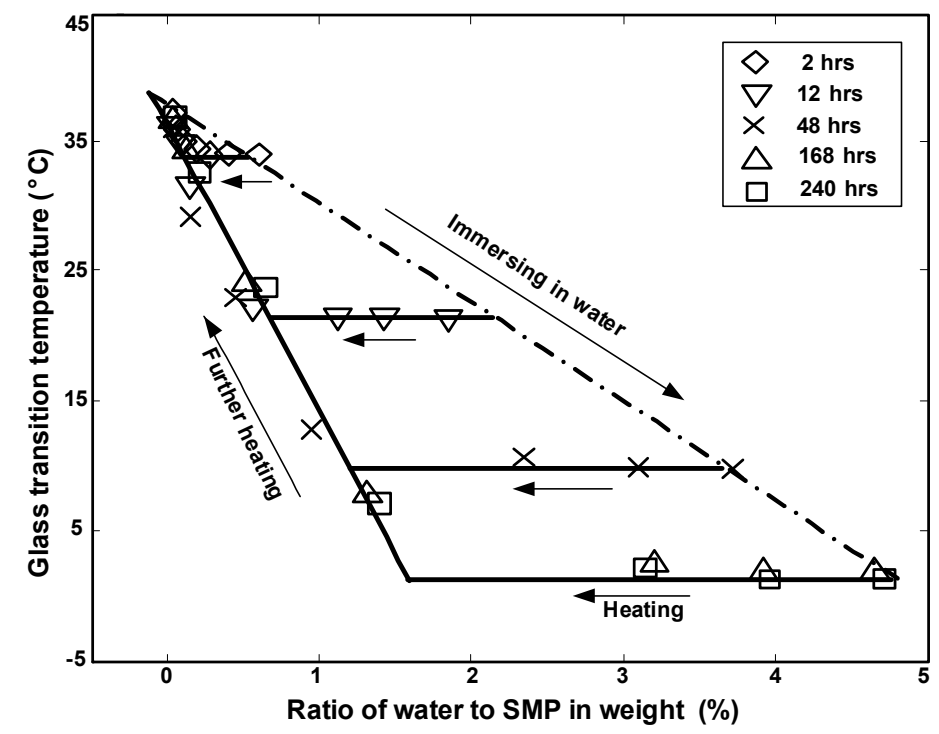

\subsubsection{Swelling}

As reported in [3], a piece of pre-deformed polystyrene (PS) is able to recover its original shape upon immersing into room temperature acetone for $16 \mathrm{~h}$. However, after shape recovery, the PS sample becomes remarkably longer than before.

Such swelling-induced volume expansion is not always undesirable [13], and may be utilized as a novel manufacturing technique in some special applications. One such application is to produce microlens array atop poly(methyl methacrylate) (PMMA) as revealed in Figure 9. Instead of following tradition lens fabrication methods, we immerse a piece of 2-dimensional or 3-dimensional PMMA with an array of pre-indented micro indents atop into room temperature ethanol. After nine hours, an array of microlens is produced [103].

\subsubsection{Dissolving}

The extreme case of softening is to remove the transition component by means of dissolving, so that the corresponding volume expansion reaches the maximum. In Figure 10, a hybrid ring is made of silicone filled with 70 vol $\%$ of sodium acetate trihydrate $\left(\mathrm{CH}_{3} \mathrm{COONa}_{3} 3 \mathrm{H}_{2} \mathrm{O}\right)$. The original star-shaped ring is pre-expanded at the melting temperature of $\mathrm{CH}_{3} \mathrm{COONa} \cdot 3 \mathrm{H}_{2} \mathrm{O}$ and then cooled back to room temperature (around $22^{\circ} \mathrm{C}$ ). Given the high volume percentage of $\mathrm{CH}_{3} \mathrm{COONa} \cdot 3 \mathrm{H}_{2} \mathrm{O}$ in the hybrid, $\mathrm{CH}_{3} \mathrm{COONa} \cdot 3 \mathrm{H}_{2} \mathrm{O}$ inclusions within silicone matrix are effectively connected, and hence the silicone matrix is virtually a kind of open-cell sponge. Upon immersing into room temperature water, $\mathrm{CH}_{3} \mathrm{COONa} \cdot 3 \mathrm{H}_{2} \mathrm{O}$ gradually dissolves. Consequently, the silicone sponge gradually recovers its original star shape. 
Figure 9. PMMA microlens arrays. (a) After indentation; (b) after immersion into room temperature ethanol; and (c) surface profiles at different stages during processing. (Reproduced with permission from [103]. Copyright 2011 The Optical Society (OSA)).
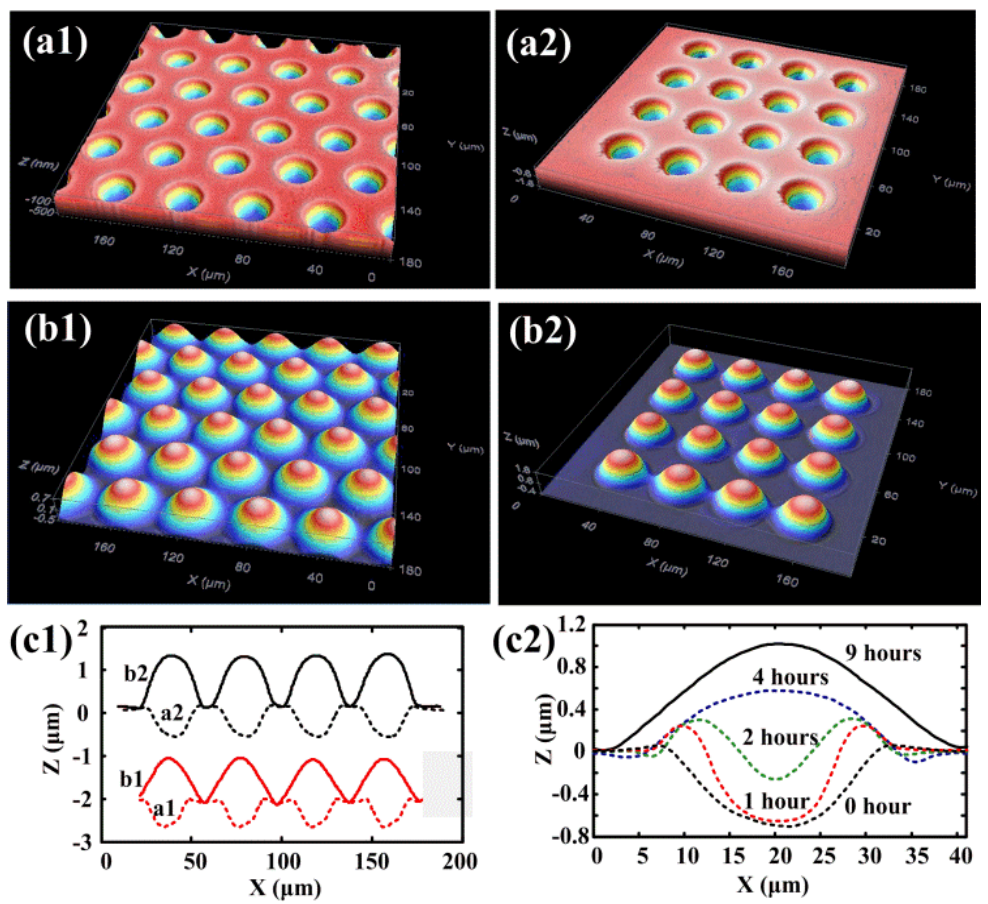

Figure 10. Shape recovery in a silicone hybrid ring filled with $70 \mathrm{vol} \%$ of $\mathrm{CH}_{3} \mathrm{COONa}_{3} \mathrm{H}_{2} \mathrm{O}$ upon immersing into room temperature water. (Reproduced with permission from [104].

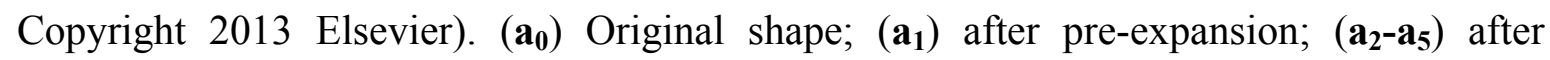
immersing into room temperature water.
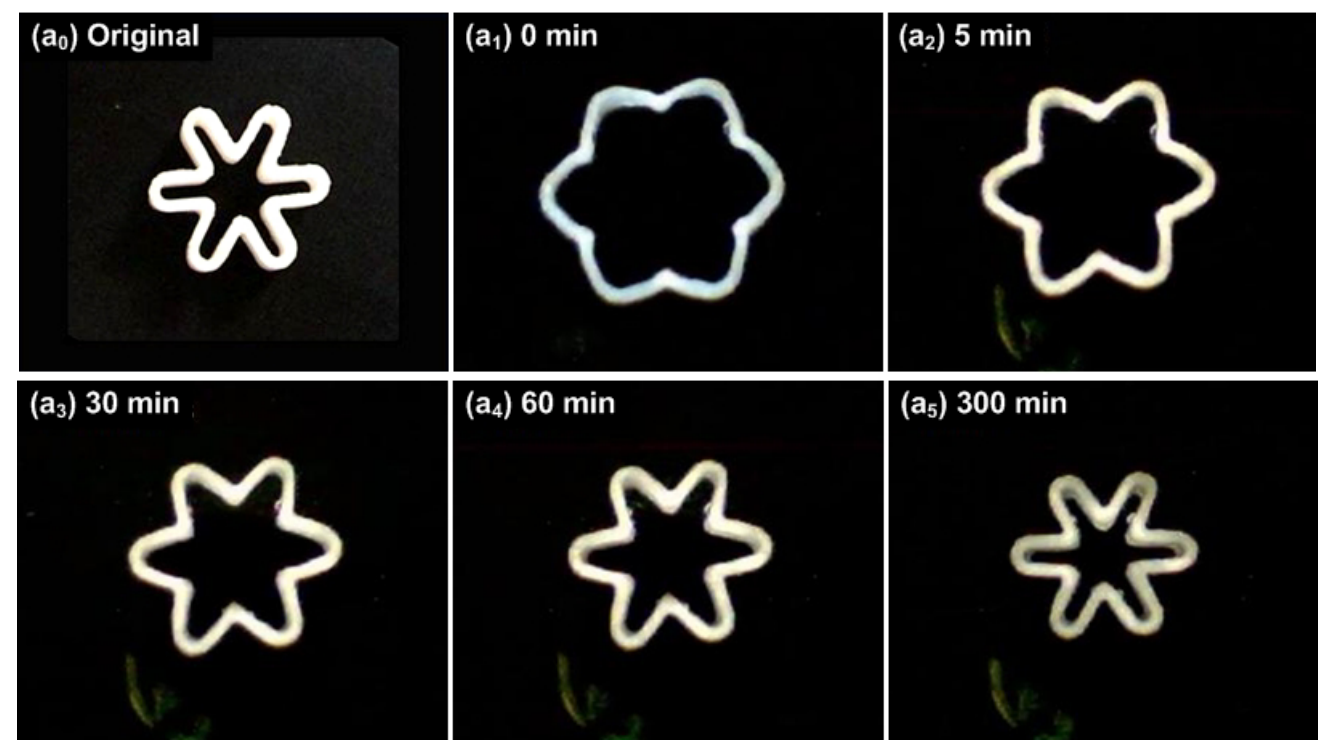

Although in the thermally induced SME, temperature variation within a piece of polymer can be minimized by means of slowly heating/cooling to maintain virtually constant temperature distribution within the whole piece of a material, the penetration nature in the chemo-responsive SME causes intrinsic 
un-uniformity within a piece of polymer, which may result in an unexpected response during shape recovery.

As reported in [3], unlike that of water penetrating into PU, the boundary between the ethanol penetrated part and un-penetrated part in PMMA is rather narrow, only a couple of $\mu \mathrm{m}$. PMMA microlens array presented in Figure 9 is achievable also due to the influence of pre-compression at room temperature so that the material right underneath the indents has a much higher ethanol penetration speed than the rest of the un-indented part. Consequently, the indented part swells significantly well before the rest and, hence, the microlens array is produced [103].

Figure 11 presents a piece of PMMA which is pre-stretched at high temperatures before immersing into room temperature ethanol. The PMMA actually curves before it finally returns to its original shape.

Figure 11. Buckling of PMMA. (a) Original shape; (b) after pre-stretching at high temperatures; and (c) after immersing into room temperature ethanol for a few hours.

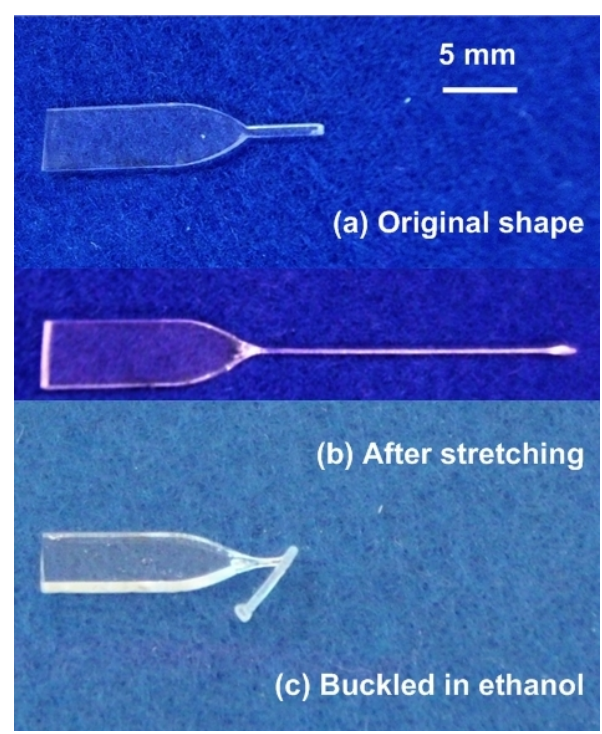

The underlying mechanism behind the unexpected curving phenomenon in pre-stretched PMMA is schematically illustrated in Figure 12 [105]. The penetration of ethanol from the outside surface inward causes a gradually increased compression force in the pre-stretched PMMA within its cross-section along its axial direction. When the compression force reaches a critical point, the piece of PMMA buckles. After a prolonged period of immersion, ethanol penetrates throughout the whole PMMA, and the PMMA recovers its original shape and becomes straight again.

As discussed earlier, the thermally and chemically induced shape recovery is generic and applicable to almost all polymers. Therefore, we may conclude that both thermo (heating) and chemo-responsive SMEs are an intrinsic feature of almost all polymeric materials, although the exact magnitude in shape recovery varies from material to material.

On the contrary, the photo-responsive and mechano-responsive SMEs need special transition components which can react to light or mechanical loading by means of softening. Hence, the photo-responsive and mechano-responsive SMEs are not commonly achievable in polymers. 
Figure 12. Illustration of underlying mechanism. (a) Original amorphous PMMA; (b) uniaxial stretching at high temperatures; (c) cooling and unloading; (d) ethanol penetrating and outer layer softening; (e) buckling at a critical penetration depth; and (f) final shape after recovery. Area in red is with ethanol. (Reproduced with permission from [105]. Copyright 2011 American Institute of Physics).

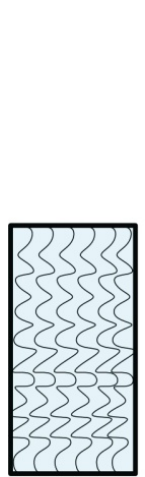

(a)

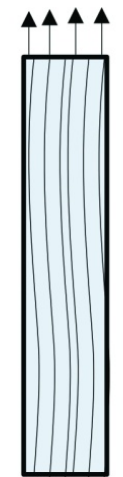

(b)

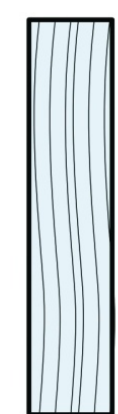

(c)

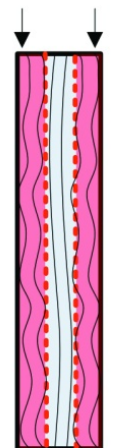

(d)

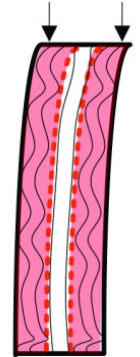

(e)

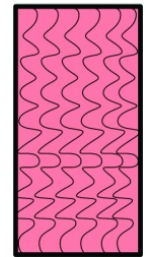

(f)

Figure 13 presents an example of the mechano-responsive SME in an elastic sponge-cupric sulfate pentahydrate $\left(\mathrm{CuSO}_{4} \cdot 5 \mathrm{H}_{2} \mathrm{O}\right)$ hybrid [88]. The elastic sponge is pre-compressed in its length direction (horizontal direction in Figure 13) and then soaked in hot supersaturated $\mathrm{CuSO}_{4} \cdot 5 \mathrm{H}_{2} \mathrm{O} /$ water solution. After cooling to let $\mathrm{CuSO}_{4} \cdot 5 \mathrm{H}_{2} \mathrm{O}$ crystallize within the pores, we obtain a piece of elastic sponge- $\mathrm{CuSO}_{4} \cdot 5 \mathrm{H}_{2} \mathrm{O}$ hybrid, which has been programmed, but in an unconventional way. When being hammered in the vertical direction, the impact smashes $\mathrm{CuSO}_{4} \cdot 5 \mathrm{H}_{2} \mathrm{O}$ crystals and thus the elastic sponge is able to recover its original shape by means of extending in the horizontal direction. Since $\mathrm{CuSO}_{4} \cdot 5 \mathrm{H}_{2} \mathrm{O}$ is able to quickly dissolve in water, this elastic sponge- $\mathrm{CuSO}_{4} \cdot 5 \mathrm{H}_{2} \mathrm{O}$ hybrid is also water-responsive [21].

Figure 13. Impact-induced shape recovery in an elastic sponge- $\mathrm{CuSO}_{4} \cdot 5 \mathrm{H}_{2} \mathrm{O}$ hybrid. (a) After programming; and (b) after being hammered in the vertical direction [88].

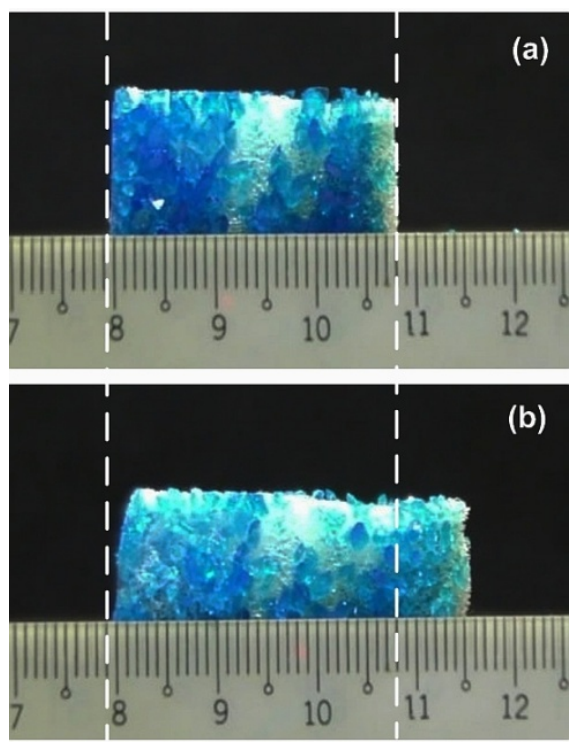


We may safely conclude that, in general, most polymers are able to respond to more than one stimulus, i.e., essentially most polymers intrinsically have the multiple stimuli-responsive SME. The nature of multiple stimuli-responsive SME in polymers provides users options for the most effective approach to trigger shape recovery in a real engineering application.

\section{Advanced Shape Memory Phenomena}

The research progress in recent years has widely expanded the traditional definition of SME. A few advanced shape memory phenomena have been discovered in polymers, which add new dimensions to the applications.

\subsection{Multiple-SME (Shape Memory Effect)}

Traditionally, SMMs are only able to switch between two shapes: one is the original shape, which is permanent, and the other is the temporary shape, which requires a programming process to fix it. It is ideal to have one or more intermediate shapes between the temporary shape and the original shape, the so-called multiple-SME (or triple-SME, if there is only one intermediate shape), for more complicated motion generation.

In some situations, multiple shapes during shape recovery can be observed due to some special mechanisms. As revealed in Figure 14, a piece of PU spiral spring is immersed into room temperature ethanol. The spring contracts after $7 \mathrm{~s}$ of immersion and then starts to expand $17 \mathrm{~s}$ later. The internal stress generated during the fabrication of the spiral spring is found to be the reason for such contraction-expansion phenomenon [102].

Figure 14. Morphing in a pre-stretched PU spring after immersing into room temperature ethanol. (a) No significant shape change in the first $7 \mathrm{~s}$; (b-f) contraction for $8 \mathrm{~s}$; and (f-j) expansion for 4 s. (Reproduced with permission from [102]. Copyright 2012 Elsevier).
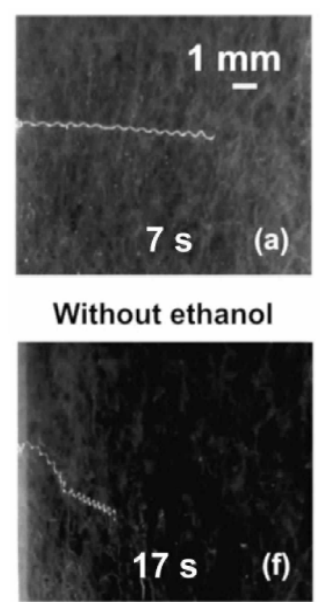
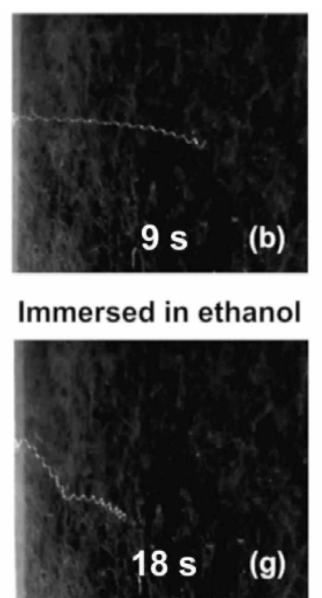
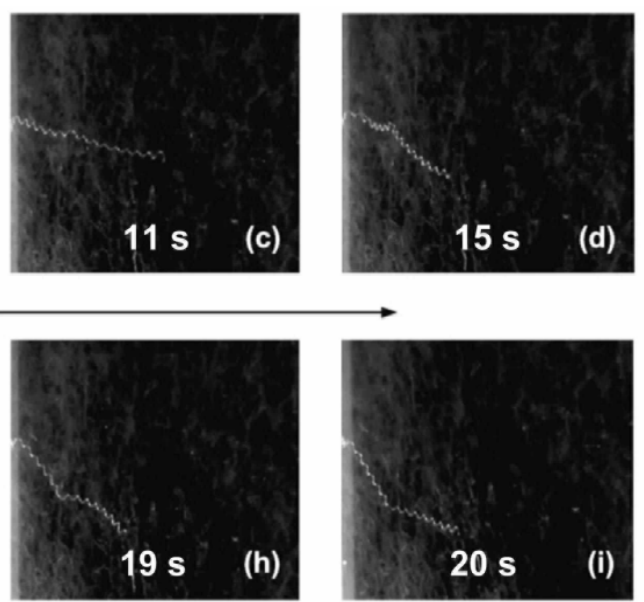
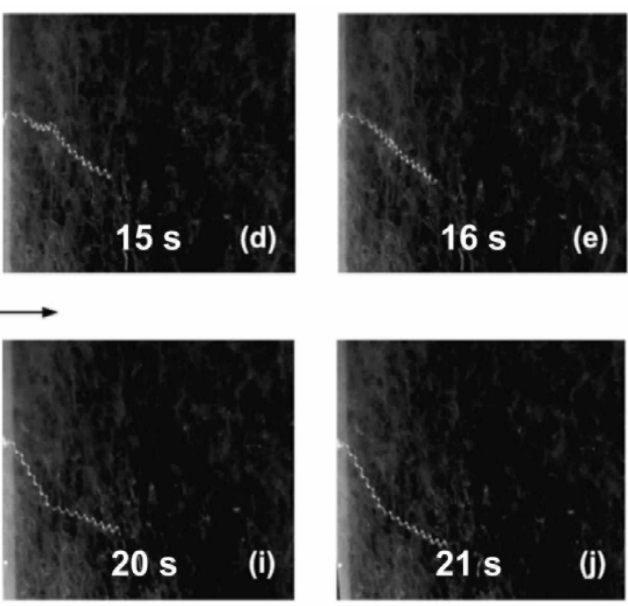

Another approach to achieve the multiple-SME is to have a gradient transition temperature [32,106]. In Figure 15, utilizing the influence of water on the $T_{\mathrm{g}}$ of the PU (as revealed in Figure 8), by means of immersing different segments of a piece of PU wire into water for different periods of time, three different segments (top, middle and bottom) have been assigned with different $T_{\mathrm{g}}$. Consequently, after 
being programmed into a " $Z$ " shape and then immersed into room temperature water, water-induced shape recovery appears in a step by step fashion [101]. The concept of polymeric composite, in which two or more layers of polymers with different transition temperatures, provides an alternative to achieve the multiple-SME [32].

Figure 15. The triple-SME in a PU wire upon immersing into room temperature water. (Reproduced with permission from [101]. Copyright 2005 American Institute of Physics).

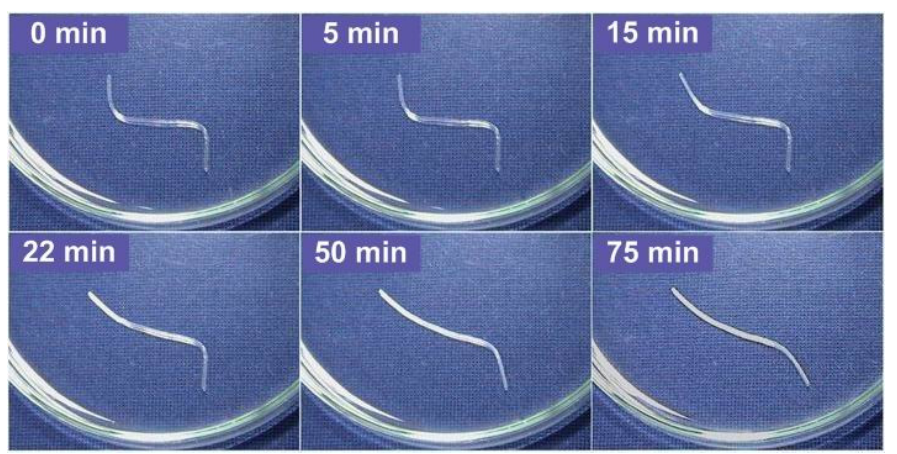

By means of having two transition components with different transition temperatures, instead of having only one as in most of previous studies, in 2006, Professor Lendlein's group demonstrated a convenient approach to achieve the triple-SME [107]. In 2010, Dr. Xie demonstrated that a polymer with a broad transition temperature range can be programmed to have more than one intermediate shape [108]. Subsequently, the underlying mechanism was revealed [109]. It was proved that the multiple-SME is an intrinsic feature of polymers and that the triple-SME can be easily achieved in most polymers by programming based on only one transition [19]. A step-by-step softening/frozen procedure during heating/cooling is the fundamental reason behind the multiple-SME.

Following these concepts, the triple-SME has been realized in a number of polymer systems [54,110-117]. Although in theory, we can achieve an infinite number of intermediate shapes $[109,118]$, the significance of the SME in each intermediate shape is reduced with the increase of the number of the intermediate shapes.

Although one-step programming has been proposed to achieve the triple-SME in [119], it is only applicable to realize some simple one directional format of motions, such as step by step contraction or extension, and is lack of the flexibility in control of the magnitude in each recovery step. Fundamentally, the triple-SME after one-step programming requires two transitions during stimulus-induced shape recovery. PTFE is a good example to demonstrate one-step programming for the triple-SME (Figure 1I). After being severely pre-stretched at room temperature (Figure 1Ib), upon heating to above its glass transition temperature, it partially recovers some residual strain (Figure 1Ic). Full shape recovery is achievable when it is further heated to its melting temperature (Figure 1Id).

A standard programming process for the multiple-SME includes more than one step. In each step, one temporary shape is fixed. As such for the triple-SME, in which there are two temporary shapes, we need to program twice, one for the intermediate shape, and the other for the final temporary shape.

Figure 16 reveals the triple-SME in a silicone-paraffin wax (PW) hybrid, in which the volume fraction of $\mathrm{PW}$ is $30 \%$ [88]. The programming procedure is as following:

- The hybrid is heated to $65^{\circ} \mathrm{C}$ and then twisted. 
- After cooling to $40{ }^{\circ} \mathrm{C}$ with the twisted shape maintained, it is bent.

- Subsequently, it is cooled to $15{ }^{\circ} \mathrm{C}$ and the constraint is removed.

Figure 16. Triple-SME in silicone-paraffin wax (PW) hybrid. (a) From twisted-bent shape to twisted shape upon immersion into $45{ }^{\circ} \mathrm{C}$ water; and (b) from twisted shape to original straight shape upon immersion into $65^{\circ} \mathrm{C}$ water [88].

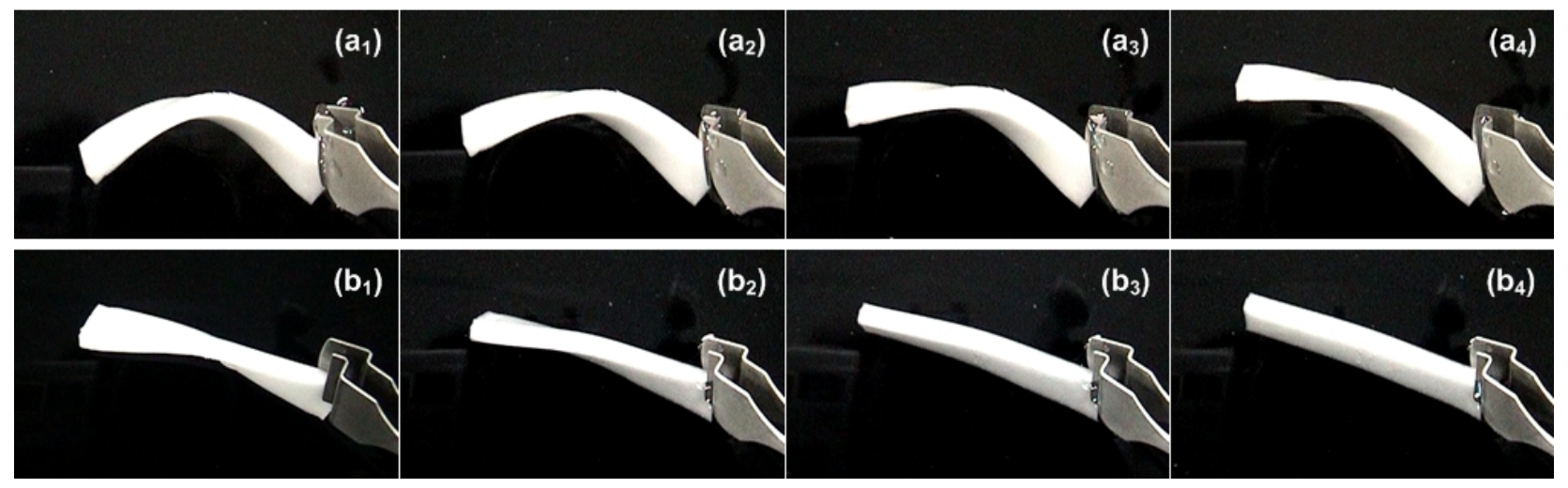

In the shape recovery process, upon immersing into $45{ }^{\circ} \mathrm{C}$ water, it is straightened (Figure 16a). Further heating by means of immersing into $65^{\circ} \mathrm{C}$ water, the hybrid is untwisted and thus fully recovers its original shape (Figure 16b).

\subsection{Temperature Memory Effect}

The temperature memory effect (TME) was originally discovered in shape memory alloys (SMAs), although a few different terms have been used since this phenomenon was first reported in 1993 [120,121]. Originally, the TME refers to the ability of a material to remember the maximum heating temperature in a previous single or cyclic heating process and to reveal this maximum temperature in a later heating process, most likely by means of examining the heat flow versus heating temperature results from a differential scanning calorimeter (DSC) test [122,123].

It is likely that the TME in polymers was first reported in [124]. Contrary to SMAs, it is the programming temperature that is meant to be memorized, and the test to reveal the TME is constrained recovery, i.e., a piece of programmed polymer is heated with the shape fixed. It was reported that the temperature corresponding to the measured maximum stress in the polymer during heating is always slightly lower than the programming temperature [108,124]. Figure 17 presents the experimental results of the TME in an EVA-based melting glue and paraffin wax. It is clear that the TME is another intrinsic feature of polymers [109], but there are many factors which may affect the TME. Among others, the exact shape of the DSC curve (e.g., single peak or multiple peaks in transition), the coefficient of thermal expansion before and after transition, and the Young's moduli before and after transition are the most influential ones. Consequently, the temperature which corresponds to the maximum stress during heating may be higher or lower than the actual programming temperature. 
Figure 17. Evolution of recovery stress against heating temperature in melting glue (a); and paraffin wax (b), which are pre-programmed at different temperatures. Inset: DSC result (heat flow versus temperature) in heating process. (Reproduced with permission from [3]. Copyright 2012 Springer).
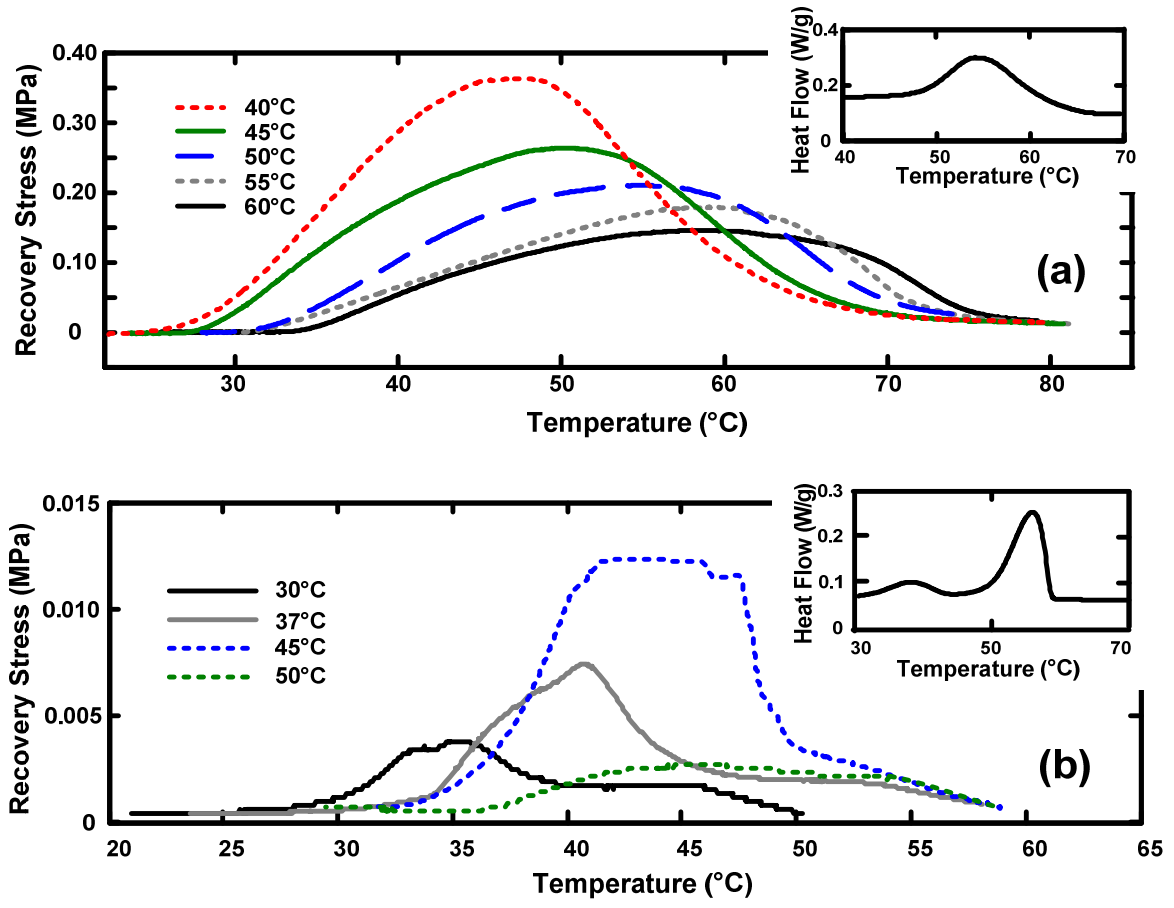

As is similar in SMAs, the aforementioned TME is not ostensibly useful in real engineering applications. However, recent study reveals that in the case of shape recovery without applying any constraint (free recovery), the maximum shape recovery occurs at around the programming temperature, i.e., a significant shape recovery occurs when the material is heated to the programming temperature, or to slightly above the programming temperature (refer to Figure 18). This new form of the TME provides a simple way to fine-tune the transition temperature to be within a very sharp temperature range $[125,126]$.

Figure 18. Illustration of shape recovery ratio/transition fraction against heating temperature. The designated 1 is programmed at $T_{1}$ and 2 is programmed at $T_{2}$. Subscript $\mathrm{S}$ stands for small deformation and subscript L stands for large deformation. (Modified from [3]).

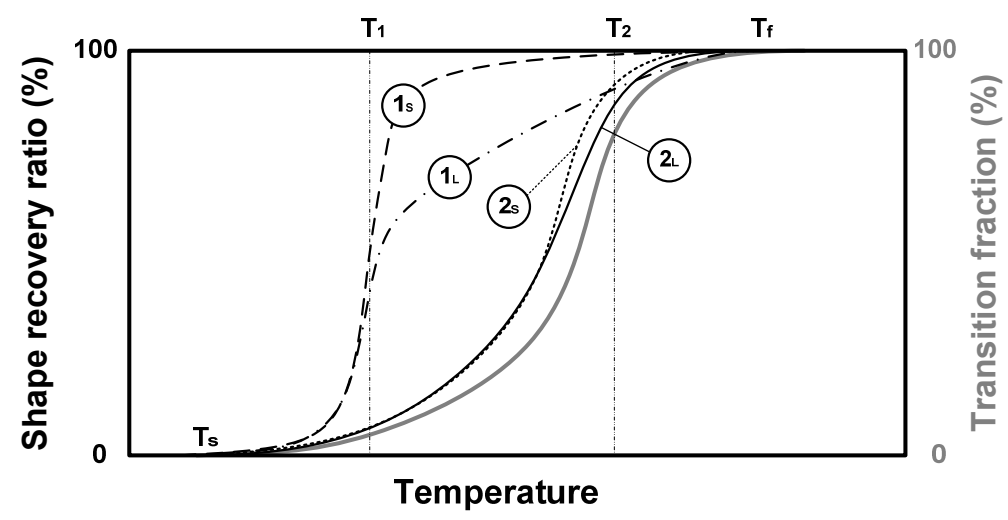


A close view of Figure 18 further reveals the strong influence of the exact magnitude of the programming strain on the significance of the TME, in particular at low programming temperatures [3]. This phenomenon can be explained as follows. When a large programming strain is applied, both the low softening temperature portion of the transition component and a part of the high softening temperature portion of the transition component are plastically distorted. As such, in the subsequent shape recovery process, heating to the programming temperature is only able to soften the low softening temperature portion of the transition component. For more shape recovery, further heating is required to soften the plastically distorted, high softening temperature portion of the transition component.

\subsection{Reversible Motion}

According to the traditional theory, the softening nature of polymers in heating-induced SME prevents the possibility of having reversible motion upon thermal cycling, except in some specially designed polymeric composites and some liquid crystals [47]. However, in recent years, reversible motion during thermal cycling has actually been reported in a couple of polymers $[29,33,34,127]$.

Since an external force (by means of either applying an external load directly or bonded to/connected with a piece of elastic component, which essentially serves as an elastic spring) is always applied in these polymers to automatically reset the temporary shape in each cycle [128,129], according to the definition in [73], it is the mechanical two-way SME. Similar to that in SMAs, the material two-way SME, in which a piece of free-standing material is able to switch between two shapes during thermal cycling, is theoretically achievable (by means of introducing an elastic stress field at micro-scale into a polymer), but has yet been realized in real practice.

It should be pointed out that:

- Strictly speaking, the reversible motion upon thermal cycling is actually the SCE.

- A special mechanism to achieve softening during cooling upon loading is required. Right now, the fundamentals are still under construction [130]. As such, unlike the aforementioned multiple-SME and TME, reversible motion is not a generic shape memory phenomenon in polymers.

- Particular attention should be paid to distinguish it from the thermal mismatch-induced reversible motion.

\section{Design of Polymeric Materials and Optimization}

In recent years, we have seen great efforts in developing new polymers and improving existing ones for tailored shape memory features, improved performance and/or new functions $[14,29,34,37,52,55,79,131-145]$. On the other hand, the SME has been discovery in many other materials beyond the traditional polymers, such as starch, maize flour and even nails $[3,146]$. Figure 19 reveals the water-responsive SME in a string of cocoon silk. Shape recovery is finished within 10-20 s. Since protein and even DNA are essentially polymer, it is no surprise to observe the SME in these materials. 
Figure 19. Water-responsive SME in cocoon silk. (a) Scanning electron microscope image of a string of commercial silk. Each piece of silk is about $10 \mu \mathrm{m}$. The scale bar is $100 \mu \mathrm{m}$; (b) after being programmed into spiral spring shape; and (c) after immersing into room temperature water for shape recovery.
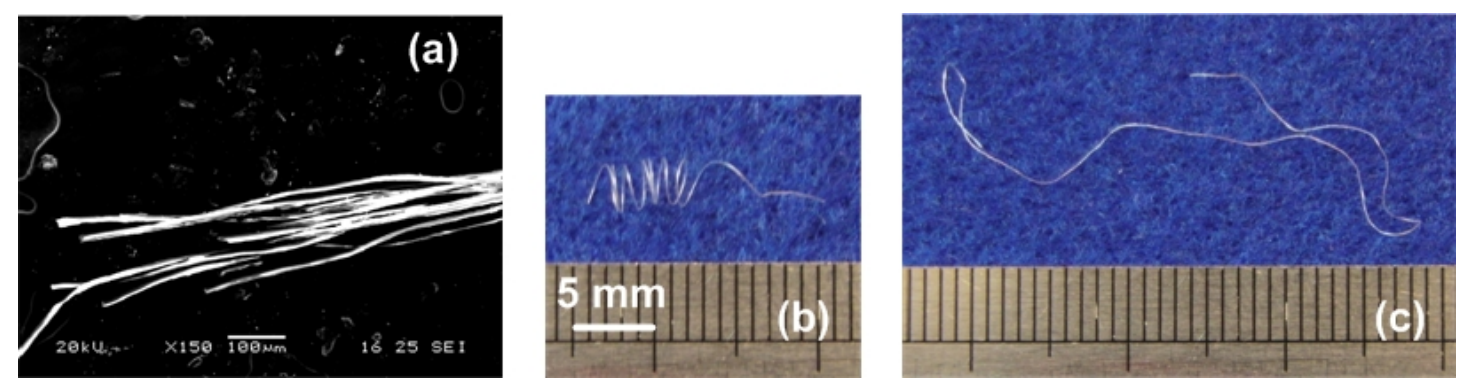

Despite these solid advancements, we cannot always easily obtain a polymeric material with the exact shape memory feature and other required properties for a particular application. Traditional synthesis techniques require not only strong chemical/polymer knowledge, but also many runs of trial and error. With the aforementioned working mechanisms in mind, we can comfortably follow simple approaches, which are accessible to even non-experts, to work out their own polymeric SMMs with the required performance or to optimize existing ones for tailored features.

\subsection{Design of Polymeric Materials}

Figure 20 reveals the thermo-responsive SME in a hybrid which is designed based on the working mechanism of DCM, in which a highly elastic sponge is selected as the elastic component (matrix) and a paraffin wax with the required activation temperature (melting temperature) as the transition component (inclusion).

Figure 20. The SME in an elastic sponge-PW hybrid. The sample is pure sponge for comparison. (a) After programming (being compressed above the melting temperature of $\mathrm{PW}$ ); (b) after heating to above the melting temperature of PW; and (c) high elasticity in the sponge (right sample).

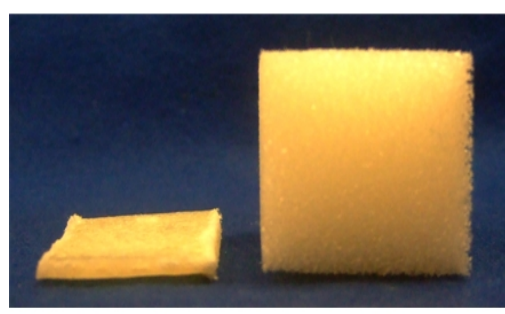

(a)

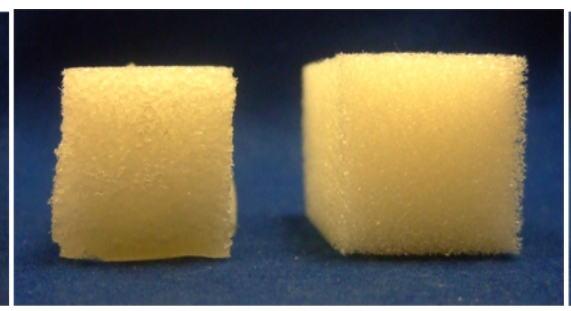

(b)

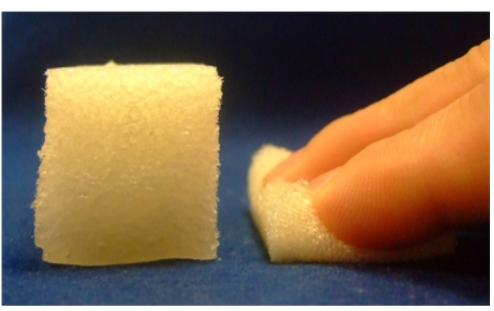

(c)

The procedure to prepare the sponge-PW hybrid is as follows. After heating to above the melting temperature of the PW, the sponge is soaked into the liquid form of PW and compressed a few times to absorb as much PW as possible. Programming is done by means of compressing the hybrid and then cooling it to below the melting temperature of PW (Figure 20a, left sample). Upon heating to above the melting temperature of PW, the sponge regains its original height (Figure 20b, left sample). It is 
obvious that the shape memory properties of this hybrid, such as, shape fixity ratio, shape recovery ratio (in free recovery) and recovery force (in constrained recovery), are determined by the selected sponge and PW and thus can be tailored. In addition, since the interaction between the elastic matrix and transition inclusion is minimized, the activation temperature of the hybrid for shape recovery can be pre-determined.

The silicone (matrix)-water (inclusion) hybrid, as shown in Figure 21, is able to achieve an activation temperature of $\pm 0{ }^{\circ} \mathrm{C}$. This is another example to reveal the flexibility of the hybrid concept in SMM design.

Figure 21. Silicone-water hybrid with a sharp transition temperature of $\pm 0{ }^{\circ} \mathrm{C}$. (a) After programming; and (b) after recovery. (Reproduced with permission from [5]. Copyright 2012 Elsevier).

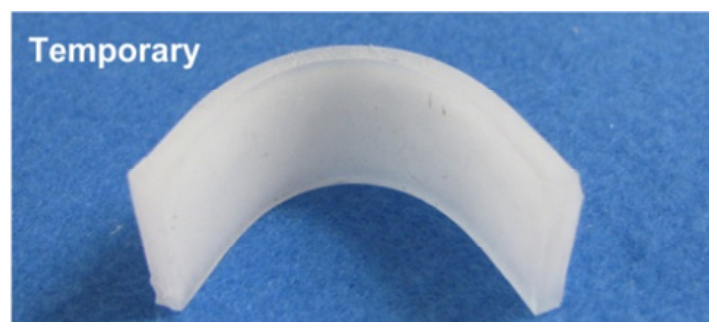

(a)

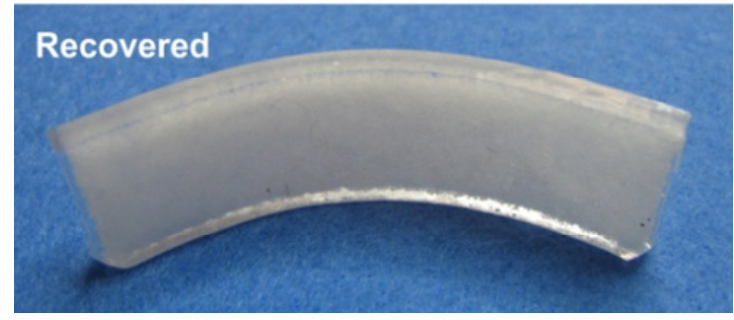

(b)

By means of selecting a paraffin wax that is brittle at room temperature as the material for inclusion, Figure 22 demonstrates the impact-induced SME in a silicone-PW hybrid.

Figure 22. Impact-induced shape recovery in silicone-PW hybrid. (a) original shape; (b) after programming; and (c) after being hammered [88].

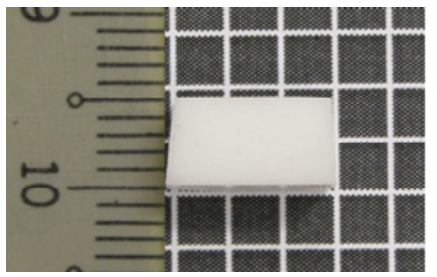

(a)

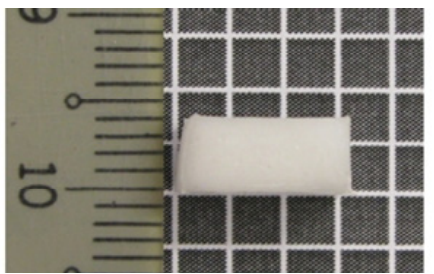

(b)

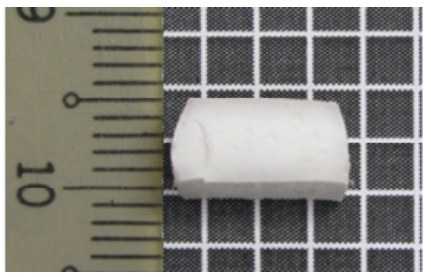

(c)

Instead of being triggered by impact, the quasi-mechano-responsive SME is achieved by gently tapping once at a local point of a piece of silicone- $\mathrm{PW}-\mathrm{CH}_{3} \mathrm{COONa} \cdot 3 \mathrm{H}_{2} \mathrm{O}$ hybrid as shown in Figure $23 \mathrm{a}_{1}$. As mentioned previously, silicone-PW hybrid is a multiple-stimuli-responsive SMM (including heating-responsive). Utilizing the latent heat generated during crystallization of $\mathrm{CH}_{3} \mathrm{COONa}_{3} 3 \mathrm{H}_{2} \mathrm{O}$, the 
silicone- $\mathrm{PW}-\mathrm{CH}_{3} \mathrm{COONa} \cdot 3 \mathrm{H}_{2} \mathrm{O}$ hybrid is able to self-heat for shape recovery Figure $23 \mathrm{~b}$. Note that the initialization of crystallization in room temperature liquid $\mathrm{CH}_{3} \mathrm{COONa} \cdot 3 \mathrm{H}_{2} \mathrm{O}$ can be triggered by a gentle disturbance, such as tapping once at a local point of the hybrid.

Figure 23. Optical (a) and infrared (b) snapshots of shape recovery sequence in a piece of silicone-PW- $\mathrm{CH}_{3} \mathrm{COONa} \cdot 3 \mathrm{H}_{2} \mathrm{O}$ hybrid triggered by gently tapping once at a local point as shown in $\left(\mathbf{a}_{1}\right)$. The unit of temperature bar in $(\mathbf{b})$ is ${ }^{\circ} \mathrm{C}$ [88].
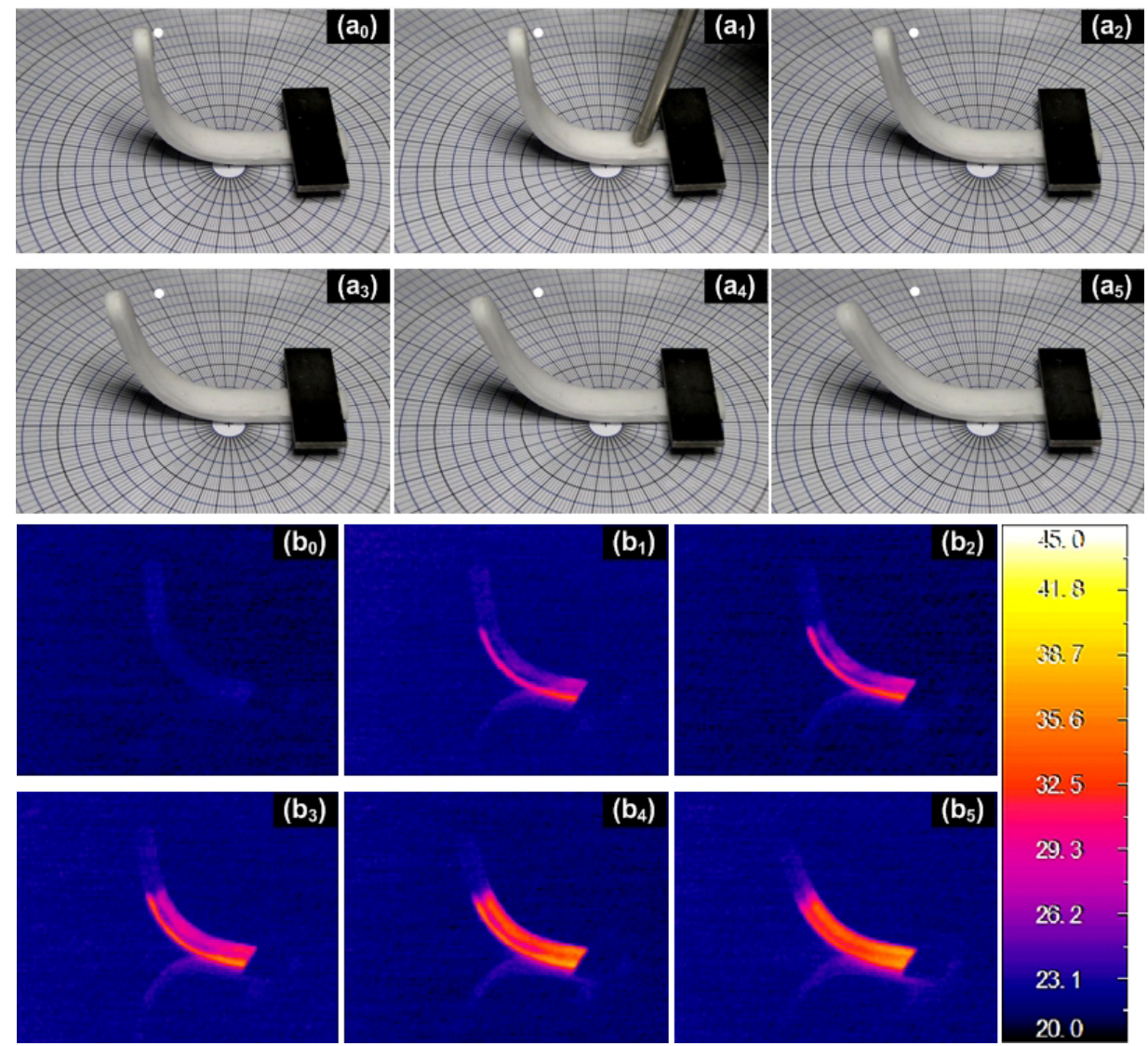

5)

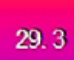

26.2

23.1

20.0

Limited success has been reported in achieving highly elastic polymers (at both above and below the transition temperature) together with the excellent SME [147]. Same as in [147], utilizing the high elasticity of Sylgard (silicone rubber), by mixing with an EVA-based melting glue, not only excellent SME and high elasticity (even better than silicone rubber itself) from low to high temperatures, but also instant and repeatable thermal-assistant healing have been realized in the hybrid [89]. Figure 24 reveals excellent rubber-like response in stretching the hybrid with and without programming.

The feature of high elasticity at around room temperature extends the application area of polymeric SMMs. For instance, based on the change in shape/morphology or color of a piece of plastic label before and after shape recovery [52,143], we can verify the authenticity of the product, as demonstrate in Figure 25 (in a real application, most likely it should be in the opposite way, i.e., heating to reveal a particular surface pattern from an initial flat surface feature or another surface pattern). However, most of the current polymeric SMMs lack the flexibility at around room temperature, so that large distortion must be avoided in these polymeric shape memory anti-counterfeit labels. 
Figure 24. Rubber-like response in cyclic uniaxial tension with (right sample)/without (left sample) programming (bending). (Reproduced with permission from [2]. Copyright 2010 Elsevier).

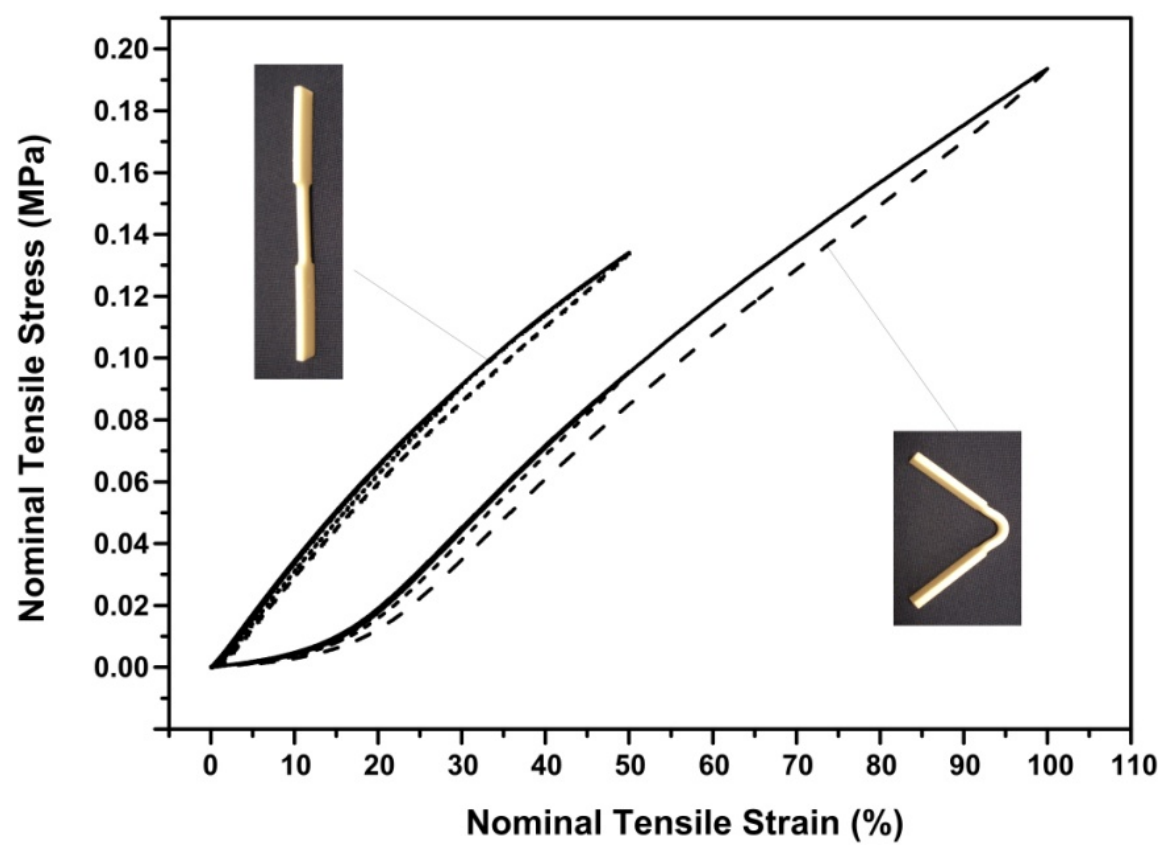

Figure 25. Polymeric anti-counterfeit label. (a) Before heating; and (b) after heating using a lighter.
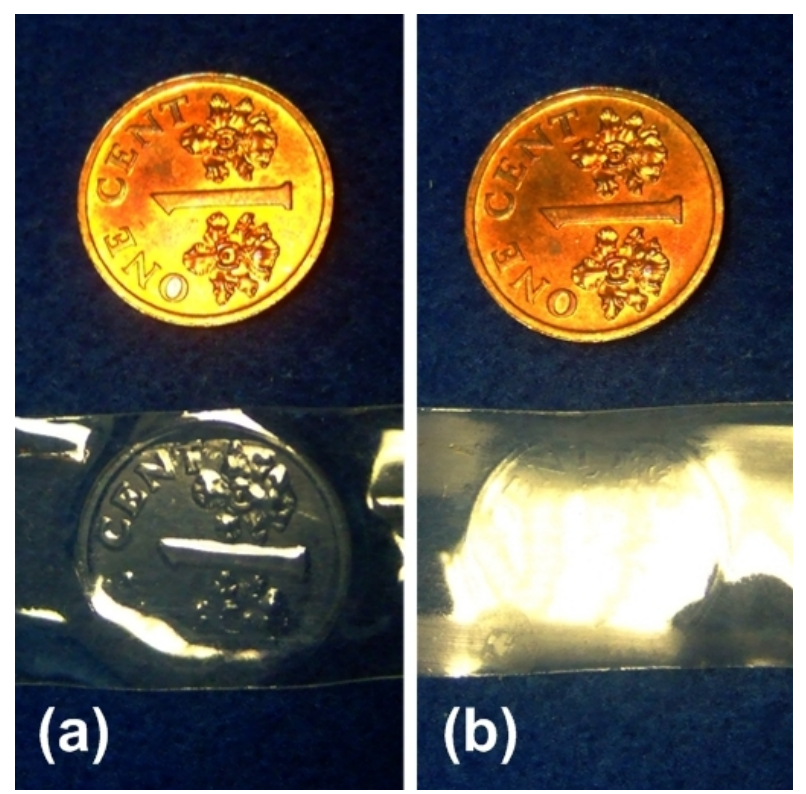

The aforementioned rubber-like SMM does not have such a problem at all. As presented in Figure 26, the label made of this hybrid is able to hold not only its original shape, but also the programmed surface morphology, after being severely bent, and thus widens the application field of the SME-based anti-counterfeit labels. 
Figure 26. Rubber-like polymeric anti-counterfeit label. (a) After impressing using a coin at high temperatures; (b) in bending; (c) after severe bending; and (d) after heating for shape recovery.

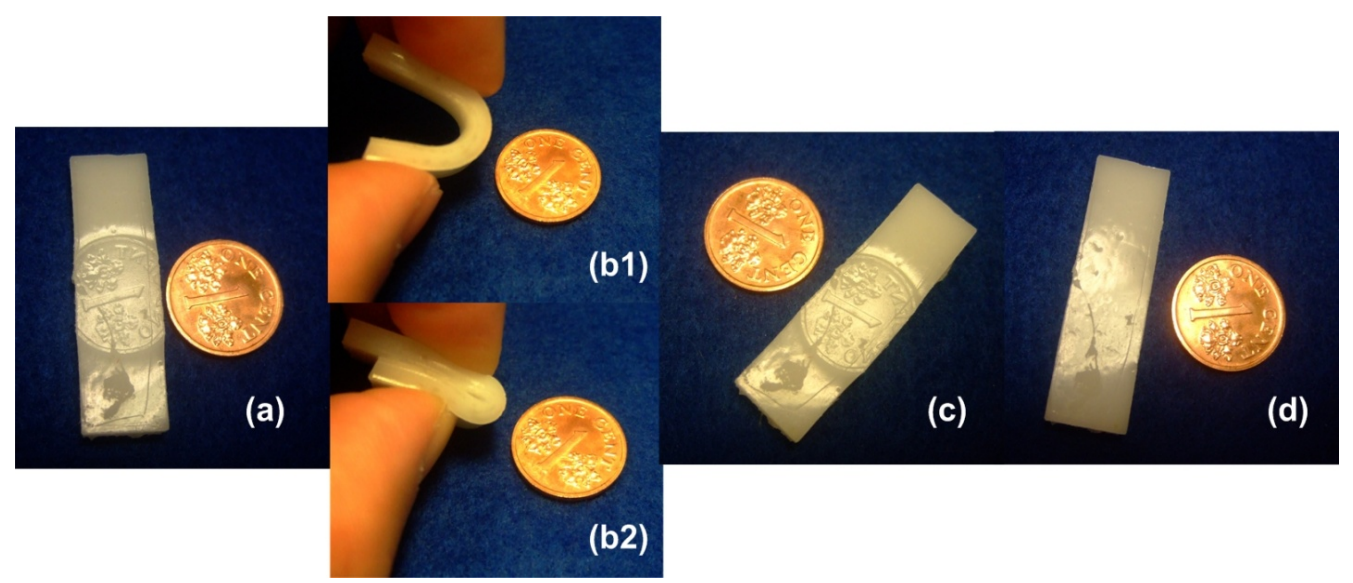

As discussed earlier, thus far reversible motion generation is only achieved in some particular polymers, in which a special mechanism to achieve softening during cooling upon loading is required. Utilizing some common physical phenomena, we can design a polymeric hybrid for reversible motion upon thermal cycling. In Figure 27, a piece of silicone-PW-glass fiber (GF) hybrid beam moves up and down against a piece of thin metallic elastic beam during thermal cycling. The volume fractions of paraffin wax and glass fiber are $29 \%$ and $1 \%$, respectively. Significant volume expansion in paraffin wax strengthens the hybrid during heating (so that pushing the elastic beam down) and the glass fiber limits the free thermal expansion of a hybrid in all directions and thus improves the increase in stiffness of the hybrid.

Figure 27. Reversible motion in silicone-PW-GF hybrid beam upon thermal cycling against a thin elastic beam. (Modified from [2]. Copyright 2010 Elsevier).

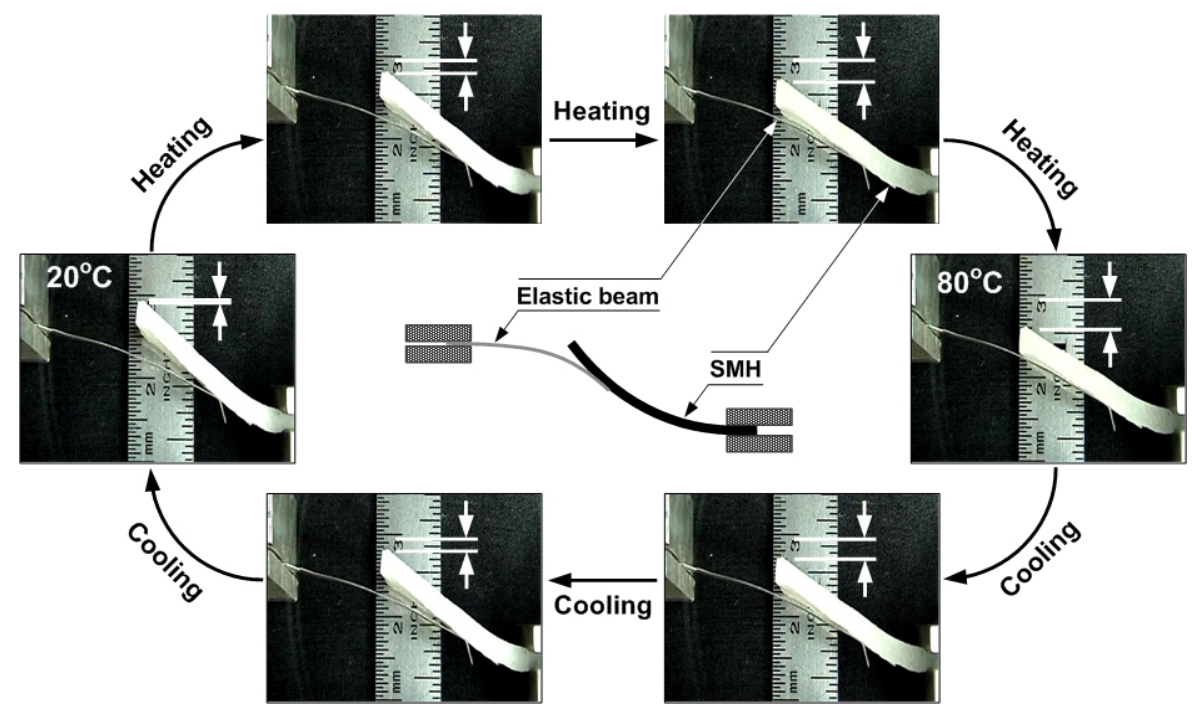

Immersing a piece of hydrogel into room temperature water, its volume is expected to expand significantly. This is the well-known swelling phenomenon, which is essentially the SCE. Instead of immersing into water, Figure 28 reveals that the hydrogel can recover its original shape (without apparent swelling) 
if the moisture level of the environment is high enough. Furthermore, heating is another approach for shape recovery in this hydrogel, so that this hydrogel is both heating and moisture- responsive [104].

Utilizing the SCE and SME in this hydrogel, in particular great volume expansion during swelling, we can obtain a polyethylene glycol (PEG)-hydrogel hybrid. PEG is water soluble, very brittle and fragile, and has very poor SME. By dropping hydrogel inside PEG water solution for a couple of hours and then drying it to get rid of redundant water, a piece of PEG-hydrogel hybrid with only $2.5 \mathrm{wt} \%$ of hydrogel is obtained. The hybrid is stiff and sturdy, and has excellent thermo-responsive SME as shown in Figure 29.

Figure 28. Moisture-responsive SME in a hydrogel. Right sample (without shape change) is for comparison. (a) Left two samples were compressed at high temperatures; (b) left sample largely recovers its original shape after $18.5 \mathrm{~h}$ at $25^{\circ} \mathrm{C}$ and humidity $54 \%$; and (c) no apparent shape change in the left sample after $18.5 \mathrm{~h}$ at $25{ }^{\circ} \mathrm{C}$ and humidity $35 \%$. (Reproduced with permission from [104]. Copyright 2013 Elsevier).

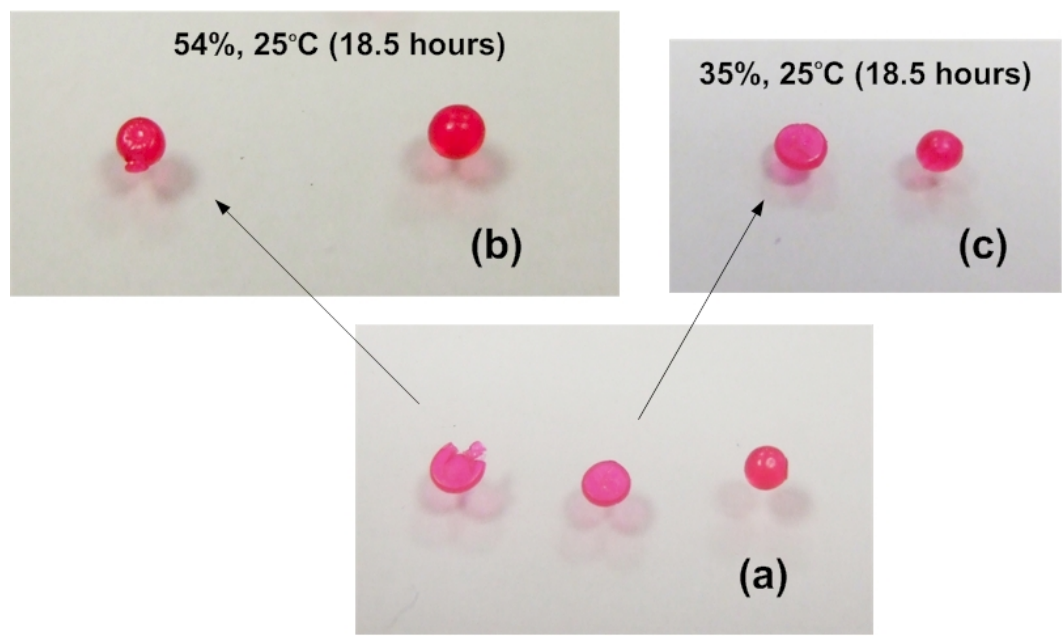

Figure 29. Thermo-responsive SME in PEG-hydrogel hybrid. (a) Original shape; (b) after programming; and (c) after heating for shape recovery. (Reproduced with permission from [104]. Copyright 2013 Elsevier).

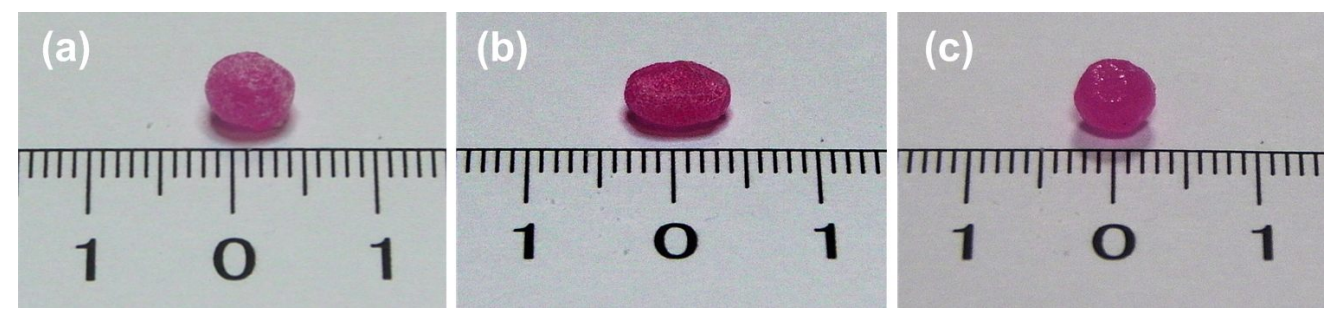

Above examples demonstrate the flexibility and versatility to design a hybrid with tailored shape memory and other features.

\subsection{Optimization}

Instead of following the tradition approaches, such as varying chemical composition, loading with fillers for reinforcement, altering synthesis process and heat/chemical treatment, 
etc. $[4,7,9,10,25,37,43,139,148,149]$, based on the principles of the above discussed working mechanisms, the performance of existing materials can be optimized by means of controlling the processing parameters in programming $[113,126,150]$.

Figure 30 illustrates the influence of the programming temperature on shape fixity ratio $\left(R_{\mathrm{f}}\right)$ and shape recovery ratio $\left(R_{\mathrm{r}}\right)$. Here, $T_{\mathrm{s}}$ and $T_{\mathrm{f}}$ are the transition start and finish temperatures, respectively; $T_{\mathrm{p}}$ and $T_{\mathrm{h}}$ are the programming temperature and heating temperature for shape recovery, respectively. The grey solid line represents the general trend for $R_{\mathrm{f}}$, provided that the following programming conditions are applied,

- The maximum programming strain is a constant;

- Unloading in programming is always conducted after cooling the material to below $T_{s}$.

Figure 30. Trends of shape fixity ratio $\left(R_{\mathrm{f}}\right)$ /shape recovery ratio $\left(R_{\mathrm{r}}\right)$ against programming temperature.

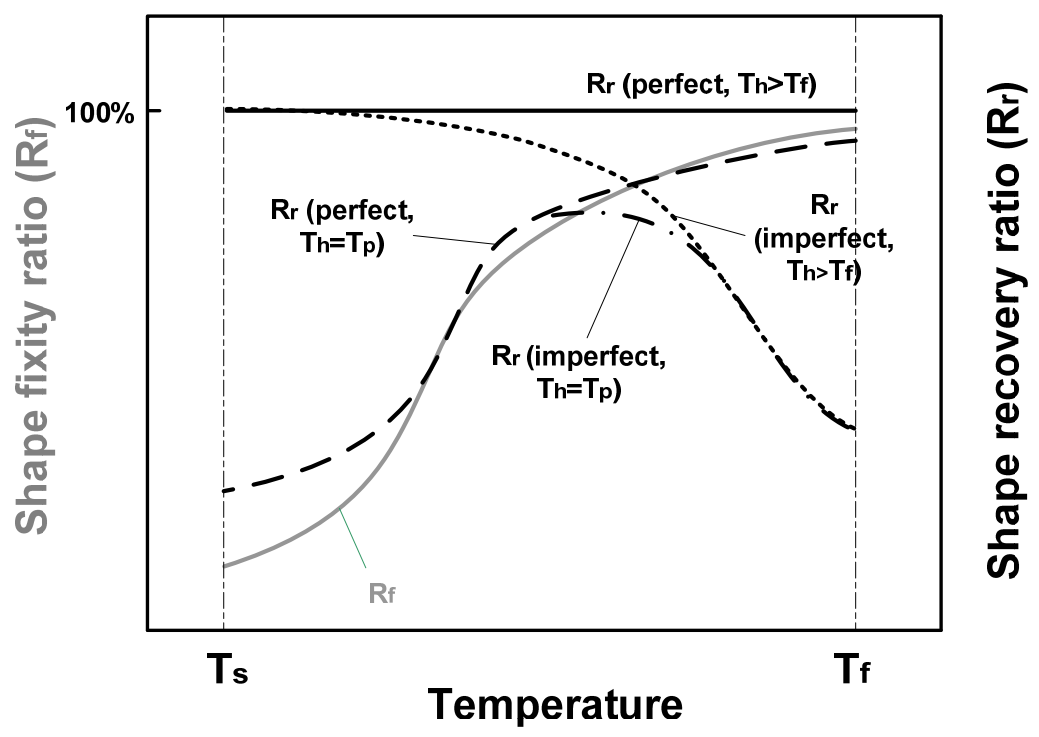

As we can see, with the increase of $T_{\mathrm{p}}, R_{\mathrm{f}}$ increases monotonically.

For an ideal polymer with the perfect SME (with the capability for $100 \%$ shape recovery), upon heating to $T_{\mathrm{p}}, R_{\mathrm{r}}$ follows the dashed black line, i.e., $R_{\mathrm{r}}$ increases with the increase of $T_{\mathrm{p}}$. However, according to [3] (also refer to Figure 18), the exact trend depends on the applied strain. Upon further heating to over $T_{\mathrm{f}}, 100 \%$ shape recovery is expected.

Please bear in mind that if we select a proper temperature and maximum strain in programming, we can dramatically narrow the transition temperature range for significant shape recovery.

In the case of imperfect SME, upon heating to $T_{\mathrm{p}}, R_{\mathrm{r}}$ follows the dashed black line, i.e., $R_{\mathrm{r}}$ increases with the increase of $T_{\mathrm{p}}$, in the low temperature range, and then follows the dash-dotted black line, i.e., $R_{\mathrm{r}}$ decreases with the increase of $T_{\mathrm{p}}$, in the high temperature range. The reason for decrease in the high temperature range is due to the non-recoverable strain developed in the elastic component. Upon further heating to above $T_{\mathrm{f}}, R_{\mathrm{r}}$ follows the dotted black line, so that $R_{r}$ decreases with the increase of $T_{\mathrm{p}}$.

The above discussion is based on the working mechanisms presented in Section 2.1, and has been experimentally verified [3]. 
Note that if the elastic component itself or a part of the elastic component is indeed a SMM, more recovery and even full recovery may be achieved upon further heating. As reported in [3] (and revealed in Figure 1I), polytetrafluoroethylene (PTEF) is a good example to demonstrate this phenomenon. The triple-SME programmed in one step is actually another example of such a phenomenon [119].

In the case of constrained recovery, recovery stress, in particular the maximum recovery stress during heating, is of our interest. According to the working mechanisms discussed previously, in particular the principle of PTM, it is possible to adjust the maximum recovery stress by means of optimizing the programming temperature [3]. Figure 31 reveals the evolution of the recovery stress of two pieces of polymethylmethacrylate (PMMA) samples upon gradually heating. These two samples were programmed at two temperatures, namely 105 and $110{ }^{\circ} \mathrm{C}$, both are within the glass transition temperature range. As we can see, the maximum recovery stress in the sample programmed at $105{ }^{\circ} \mathrm{C}$ is about twice as high as that in the sample programmed at $110^{\circ} \mathrm{C}$.

Figure 31. Evolution of recovery stress in PMMA upon heating. (a) Recovery stress versus heating temperature curve; and (b) DSC curve during heating (heating rate: $10{ }^{\circ} \mathrm{C} / \mathrm{min}$ ). Samples were pre-stretched to a maximum strain of $100 \%$ at a strain rate of $0.001 \mathrm{~s}^{-1}$ at 105 and $110^{\circ} \mathrm{C}$, respectively. (Modified from [3]).

(a)

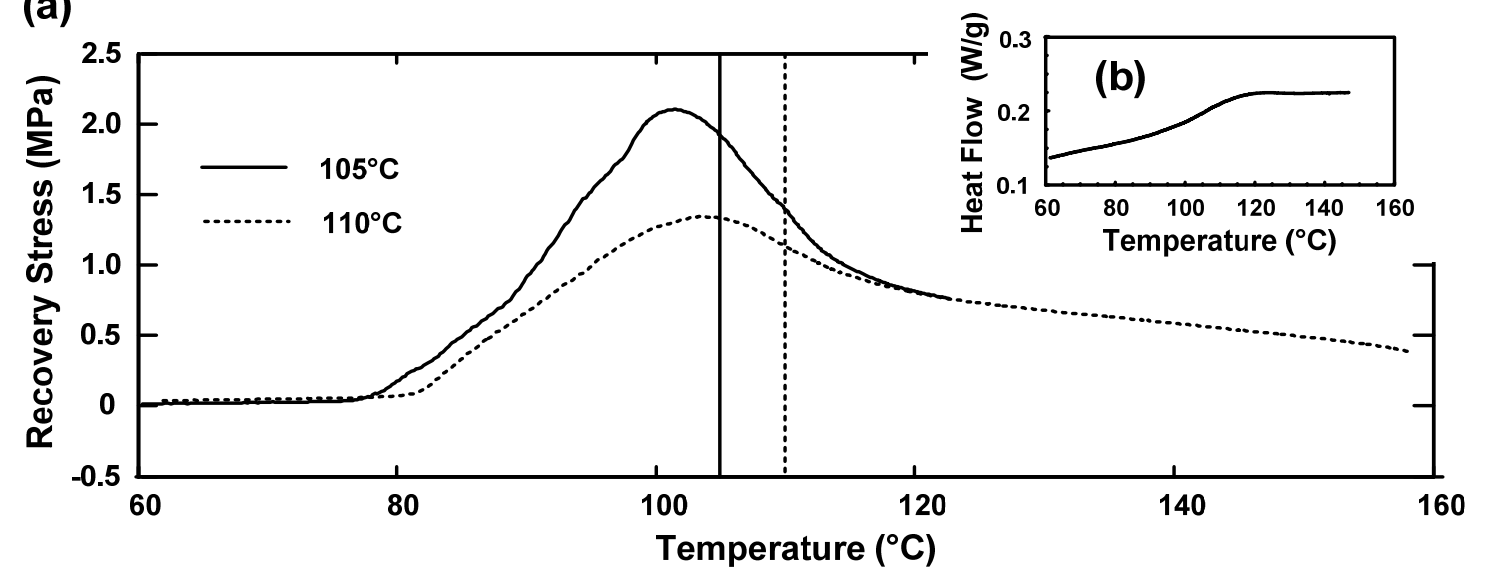

The SME has been used for anti-counterfeit application, and products are now available in the market. However, switching between two shapes may not be enough to prevent any attempt for duplication. Through optimizing the programming parameters, the multiple-SME can greatly enhance the security level by means of having one or more intermediate shapes/features upon gradually heating.

As revealed in Figure 32a, a piece of PS, which has been programmed for the triple-SME, shows the same surface feature (but mirror image) as one side of a Singapore cent coin at room temperature. After being heated to $80{ }^{\circ} \mathrm{C}$, the surface feature (also mirror image) of the other side of the coin emerges, Figure 32b. After further heating inside boiling water, the initial surface feature disappears while the second feature occupies the sample surface, Figure 32c. Using a lighter to heat the sample further, the sample surface becomes flat and featureless, Figure 32d. The intermediate image, which only appears within a pre-determined temperature range, serves as a kind of water mark to enhance the difficulty for duplication. 
Figure 32. Demonstration of the step-by-step recovery in PS. (a) After programming; (b) after heating to about $80{ }^{\circ} \mathrm{C}$; (c) after heating by boiling water; and (d) after further heating using a lighter.

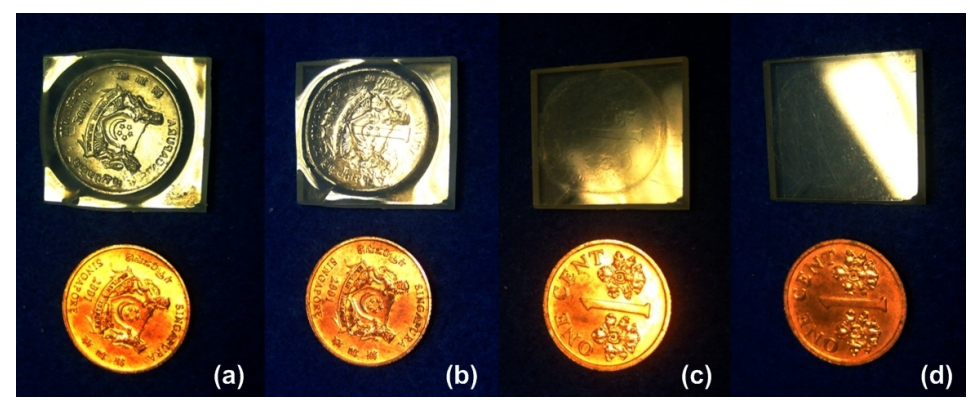

\section{Conclusions}

This review paper summarizes the very recent progress in the study of the underlying mechanisms behind the SME and some newly discovered shape memory phenomena in polymers. Taking heating-responsive SME as an example, three generic working mechanisms are presented. In addition, three categories of the chemo-responsive SME are discussed in terms of volume expansion. Other types of stimuli are briefly addressed. It is revealed that most polymers, if not all, are naturally thermo(heating)/chemo-responsive SMM. As we can see, a good understanding of the fundamentals behind various types of shape memory phenomena in polymers is not only useful in design/synthesis of new polymeric SMMs with tailored performance, but is also helpful in optimization of the existing ones, and thus remarkably widens the application field of polymeric SMMs.

\section{Acknowledgements}

This work is financially supported (partially) by the National Natural Science Foundation of China (NSFC 51303070) and China Postdoctoral Science Foundation (1721110233), China.

\section{Conflicts of Interest}

The authors declare no conflict of interest.

\section{Reference}

1. Otsuka, K.; Wayman, C.M. Shape Memory Materials; Cambridge University Press: Cambridge, UK, 1998; pp. 36-38.

2. Huang, W.M.; Ding, Z.; Wang, C.C.; Wei, J.; Zhao, Y.; Purnawali, H. Shape memory materials. Mater. Today 2010, 13, 54-61.

3. Huang, W.M.; Zhao, Y.; Wang, C.C.; Ding, Z.; Purnawali, H.; Tang, C.; Zhang, J.L. Thermo/chemo-responsive shape memory effect in polymers: A sketch of working mechanisms, fundamentals and optimization. J. Polym. Res. 2012, 19, 9952, doi:10.1007/s10965-012-9952-z.

4. Lendlein, A. Shape-Memory Polymers; Springer-Verlag: Heidelberg, Germany, 2010.

5. Sun, L.; Huang, W.M.; Ding, Z.; Zhao, Y.; Wang, C.C.; Purnawali, H.; Tang, C. Stimulus-responsive shape memory materials: A review. Mater. Des. 2012, 33, 577-640. 
6. Funakubo, H. Shape Memory Alloys; Gordon and Breach Science Publishers: New York, NY, USA, 1987.

7. Gunes, I.S.; Jana, S.C. Shape memory polymers and their nanocomposites: A review of science and technology of new multifunctional materials. J. Nanosci. Nanotechnol. 2008, 8, 1616-1637.

8. Zhao, Q.; Kelch, S.; Lendlein, A. Shape-memory polymers with multiple transitions: Complex actively moving polymers. Soft Mater. 2013, 9, 1744-1755.

9. Mather, P.T.; Luo, X.F.; Rousseau, I.A. Shape memory polymer research. Annu. Rev. Mater. Res. 2009, 39, 445-471.

10. Xie, T. Recent advances in polymer shape memory. Polymer 2011, 52, 4985-5000.

11. Wang, C.C.; Huang, W.M.; Ding, Z.; Zhao, Y.; Purnawali, H. Cooling-/water-responsive shape memory hybrids. Compos. Sci. Technol. 2012, 72, 1178-1182.

12. Yakacki, C.M.; Satarkar, N.S.; Gall, K.; Likos, R.; Hilt, J.Z. Shape-memory polymer networks with $\mathrm{Fe}_{3} \mathrm{O}_{4}$ nanoparticles for remote activation. J. Appl. Polym. Sci. 2009, 112, 3166-3176.

13. Lu, H.B. A simulation method to analyze chemo-mechanical behavior of swelling-induced shape-memory polymer in response to solvent. J. Appl. Polym. Sci. 2012, 123, 1137-1146.

14. Zhu, Y.; Hu, J.L.; Luo, H.S.; Young, R.J.; Deng, L.B.; Zhang, S.; Fan, Y.; Ye, G.D. Rapidly switchable water-sensitive shape-memory cellulose/elastomer nano-composites. Soft Matter 2012, 8, 2509-2517.

15. Beloshenko, V.A.; Varyukhin, V.N.; Voznyak, Y.V. The shape memory effect in polymers. Russ. Chem. Rev. 2005, 74, 265-283.

16. Razzaq, M.Y.; Behl, M.; Lendlein, A. Magnetic memory effect of nanocomposites. Adv. Funct. Mater. 2012, 22, 184-191.

17. Luo, X.F.; Mather, P.T. Conductive shape memory nanocomposites for high speed electrical actuation. Soft Matter 2010, 6, 2146-2149.

18. He, Z.W.; Satarkar, N.; Xie, T.; Cheng, Y.T.; Hilt, J.Z. Remote controlled multishape polymer nanocomposites with selective radiofrequency actuations. Adv. Mater. 2011, 23, 3192-3196.

19. Huang, W.M.; Yang, B.; Fu, Y.Q. Polyurethane Shape Memory Polymers; CRC Press: Boca Raton, FL, USA, 2011; pp. 325-340.

20. Huang, W.M.; Yang, B.; Zhao, Y.; Ding, Z. Thermo-moisture responsive polyurethane shape-memory polymer and composites: A review. J. Mater. Chem. 2010, 20, 3367-3381.

21. Fan, K.; Huang, W.M.; Wang, C.C.; Ding, Z.; Zhao, Y.; Purnawali, H.; Liew, K.C.; Zheng, L.X. Water-responsive shape memory hybrid: Design concept and demonstration. Express Polym. Lett. 2011, 5, 409-416.

22. Feng, Y.K.; Behl, M.; Kelch, S.; Lendlein, A. Biodegradable multiblock copolymers based on oligodepsipeptides with shape-memory properties. Macromol. Biosci. 2009, 9, 45-54.

23. Jiang, H.Y.; Kelch, S.; Lendlein, A. Polymers move in response to light. Adv. Mater. 2006, 18, 1471-1475.

24. Lendlein, A.; Behl, M. Shape-memory polymers for biomedical applications. Adv. Sci. Technol. 2009, 54, 96-102.

25. Lendlein, A.; Zotzmann, J.; Feng, Y.K.; Alteheld, A.; Kelch, S. Controlling the switching temperature of biodegradable, amorphous, shape-memory poly(rac-lactide)urethane networks by incorporation of different comonomers. Biomacromolecules 2009, 10, 975-982. 
26. Shanmuganathan, K.; Capadona, J.R.; Rowan, S.J.; Weder, C. Stimuli-responsive mechanically adaptive polymer nanocomposites. ACS Appl. Mater. Interface 2010, 2, 165-174.

27. Kim, Y.B.; Chung, C.W.; Kim, H.W.; Rhee, Y.H. Shape memory effect of bacterial poly[(3-hydroxybutyrate)-co-(3-hydroxyvalerate)]. Macromol. Rapid Comm. 2005, 26, 1070-1074.

28. Mohr, R.; Kratz, K.; Weigel, T.; Lucka-Gabor, M.; Moneke, M.; Lendlein, A. Initiation of shape-memory effect by inductive heating of magnetic nanoparticles in thermoplastic polymers. Proc. Natl. Acad. Sci. USA 2006, 103, 3540-3545.

29. Zotzmann, J.; Behl, M.; Hofmann, D.; Lendlein, A. Reversible triple-shape effect of polymer networks containing polypentadecalactone- and poly( $\varepsilon$-caprolactone)-segments. Adv. Mater. 2010, 22, 3424-3429.

30. Luo, H.S.; Hu, J.L.; Zhu, Y.; Zhang, S.; Fan, Y.; Ye, G.D. Achieving shape memory: Reversible behaviors of cellulose-pu blends in wet-dry cycles. J. Appl. Polym. Sci. 2012, 125, 657-665.

31. Bellin, I.; Kelch, S.; Lendlein, A. Dual-shape properties of triple-shape polymer networks with crystallizable network segments and grafted side chains. J. Mater. Chem. 2007, 17, 2885-2891.

32. Xie, T.; Xiao, X.C.; Cheng, Y.T. Revealing triple-shape memory effect by polymer bilayers. Macromol. Rapid Comm. 2009, 30, 1823-1827.

33. Qin, H.; Mather, P.T. Combined one-way and two-way shape memory in a glass-forming nematic network. Macromolecules 2008, 42, 273-280.

34. Chung, T.; Romo-Uribe, A.; Mather, P.T. Two-way reversible shape memory in a semicrystalline network. Macromolecules 2008, 41, 184-192.

35. Jung, D.H.; Jeong, H.M.; Kim, B.K. Organic-inorganic chemical hybrids having shape memory effect. J. Mater. Chem. 2010, 20, 3458-3466.

36. Luo, X.; Mather, P.T. Triple-shape polymeric composites (TSPCS). Adv. Funct. Mater. 2010, 20, 2649-2656.

37. Luo, H.S.; Hu, J.L.; Zhu, Y. Tunable shape recovery of polymeric nano-composites. Mater. Lett. 2011, 65, 3583-3585.

38. Pretsch, T. Triple-shape properties of a thermoresponsive poly(ester urethane). Smart Mater. Struct. 2010, 19, doi:10.1088/0964-1726/19/1/015006.

39. Small, W.; Buckley, P.R.; Wilson, T.S.; Benett, W.J.; Hartman, J.; Saloner, D.; Maitland, D.J. Shape memory polymer stent with expandable foam: A new concept for endovascular embolization of fusiform aneurysms. IEEE Trans. Bio. Med. Eng. 2007, 54, 1157-1160.

40. Sokolowski, W.; Metcalfe, A.; Hayashi, S.; Yahia, L.; Raymond, J. Medical applications of shape memory polymers. Biomed. Mater. 2007, 2, S23-S27.

41. Sortino, S. Photoactivated nanomaterials for biomedical release applications. J. Mater. Chem. 2012, 22, 301-318.

42. Wischke, C.; Neffe, A.T.; Steuer, S.; Lendlein, A. Evaluation of a degradable shape-memory polymer network as matrix for controlled drug release. J. Control. Release 2009, 138, 243-250.

43. Yakacki, C.M.; Shandas, R.; Safranski, D.; Ortega, A.M.; Sassaman, K.; Gall, K. Strong, tailored, biocompatible shape-memory polymer networks. Adv. Funct. Mater. 2008, 18, 2428-2435.

44. Yang, B.; Huang, W.M.; Li, C.; Li, L.; Chor, J.H. Qualitative separation of the effects of carbon nano-powder and moisture on the glass transition temperature of polyurethane shape memory polymer. Scr. Mater. 2005, 53, 105-107. 
45. Tobushi, H.; Hayashi, S.; Ikai, A.; Hara, H. Thermomechanical properties of shape memory polymers of polyurethane series and their applications. J. Phys. 1996, 6, 377-384.

46. Tobushi, H.; Hayashi, S.; Pieczyska, E.; Date, K.; Nishimura, Y. Three-way actuation of shape memory composite. Arch. Mech. 2011, 63, 443-457.

47. Westbrook, K.K.; Mather, P.T.; Parakh, V.; Dunn, M.L.; Ge, Q.; Lee, B.M.; Qi, H.J. Two-way reversible shape memory effects in a free-standing polymer composite. Smart Mater. Struct. 2011, 20, doi:10.1088/0964-1726/20/6/065010.

48. Dietsch, B.; Tong, T. A review-Features and benefits of shape memory polymers (SMPS). J. Adv. Mater. 2007, 39, 3-12.

49. Hu, J.L.; Meng, H.P.; Li, G.Q.; Ibekwe, S.I. A review of stimuli-responsive polymers for smart textile applications. Smart Mater. Struct. 2012, 21, doi:10.1088/0964-1726/21/5/053001.

50. Havens, E.; Snyder, E.A.; Tong, T.H. Light-activated shape memory polymers and associated applications. Smart Struct. Mater. 2005 Ind. Commerc. Appl. Smart Struct. Technol. 2005, 5762, 48-55.

51. Sokolowski, W.M.; Tan, S.C. Advanced self-deployable structures for space applications. J. Spacecr. Rocket. 2007, 44, 750-754.

52. Pretsch, T.; Ecker, M.; Schildhauer, M.; Maskos, M. Switchable information carriers based on shape memory polymer. J. Mater. Chem. 2012, 22, 7757-7766.

53. Small, W.; Singhal, P.; Wilson, T.S.; Maitland, D.J. Biomedical applications of thermally activated shape memory polymers. J. Mater. Chem. 2010, 20, 3356-3366.

54. Behl, M.; Lendlein, A. Triple-shape polymers. J. Mater. Chem. 2010, 20, 3335-3345.

55. Yakacki, C.M.; Shandas, R.; Lanning, C.; Rech, B.; Eckstein, A.; Gall, K. Unconstrained recovery characterization of shape-memory polymer networks for cardiovascular applications. Biomaterials 2007, 28, 2255-2263.

56. Lendlein, A.; Kelch, S. Shape-memory polymers as stimuli-sensitive implant materials. Clin. Hemorheol. Microcirc. 2005, 32, 105-116.

57. Alarcon, C.D.H.; Pennadam, S.; Alexander, C. Stimuli responsive polymers for biomedical applications. Chem. Soc. Rev. 2005, 34, 276-285.

58. Chaterji, S.; Kwon, I.K.; Park, K. Smart polymeric gels: Redefining the limits of biomedical devices. Prog. Polym. Sci. 2007, 32, 1083-1122.

59. Buckley, P.R.; McKinley, G.H.; Wilson, T.S.; Small, W.; Benett, W.J.; Bearinger, J.P.; McElfresh, M.W.; Maitland, D.J. Inductively heated shape memory polymer for the magnetic actuation of medical devices. IEEE Trans. Bio. Med. Eng. 2006, 53, 2075-2083.

60. Davis, K.A.; Burke, K.A.; Mather, P.T.; Henderson, J.H. Dynamic cell behavior on shape memory polymer substrates. Biomaterials 2011, 32, 2285-2293.

61. Feninat, E.F.; Laroche, G.; Fiset, M.; Mantovani, D. Shape memory materials for biomedical applications. Adv. Eng. Mater. 2002, 4, 91-104.

62. Huang, W.M. Thermo-moisture responsive polyurethane shape memory polymer for biomedical devices. Open Med. Dev. J. 2010, 2, 11-19.

63. Huang, W.M.; Yang, B.; Liu, N.; Phee, S.J. Water-responsive programmable shape memory polymer devices. Int. Conf. Smart Mater. Nanotechnol. Eng. 2007, 6423, doi:10.1117/12.779663. 
64. Metcalfe, A.; Desfaits, A.C.; Salazkin, I.; Yahia, L.; Sokolowski, W.M.; Raymond, J. Cold hibernated elastic memory foams for endovascular interventions. Biomaterials 2003, 24, 491-497.

65. Serrano, M.C.; Carbajal, L.; Ameer, G.A. Novel biodegradable shape-memory elastomers with drug-releasing capabilities. Adv. Mater. 2011, 23, 2211-2215.

66. Feng, Y.K.; Zhang, S.F.; Wang, H.Y.; Zhao, H.Y.; Lu, J.; Guo, J.T.; Behl, M.; Lendlein, A. Biodegradable polyesterurethanes with shape-memory properties for dexamethasone and aspirin controlled release. J. Control. Release 2011, 152, E21-E23.

67. Feng, Y.K.; Zhang, S.F.; Wang, H.Y.; Zhao, H.Y.; Lu, J.; Guo, J.T.; Behl, M.; Lendlein, A. Drug release from biodegradable polyesterurethanes with shape-memory effect. J. Control. Release 2011, 152, E20-E21.

68. Wischke, C.; Tripodo, G.; Choi, N.Y.; Lendlein, A. Hydrolytic degradation behavior of poly(rac-lactide)-block-poly(propylene glycol)-block-poly(rac-lactide) dimethacrylate derived networks designed for biomedical applications. Macromol. Biosci. 2011, 11, 1637-1646.

69. Xue, L.; Dai, S.Y.; Li, Z. Synthesis and characterization of elastic star shape-memory polymers as self-expandable drug-eluting stents. J. Mater. Chem. 2012, 22, 7403-7411.

70. Li, G.; Fei, G.X.; Xia, H.S.; Han, J.J.; Zhao, Y. Spatial and temporal control of shape memory polymers and simultaneous drug release using high intensity focused ultrasound. J. Mater. Chem. 2012, 22, 7692-7696.

71. Miyazaki, S.; Fu, Y.Q.; Huang, W.M. Thin Film Shape Memory Alloys: Fundamentals and Device Applications; Cambridge University Press: New York, NY, USA, 2009.

72. Ge, Y.L.; Heczko, O.; Soderberg, O.; Hannula, S.P. Magnetic domain evolution with applied field in a Ni-Mn-Ga magnetic shape memory alloy. Scr. Mater. 2006, 54, 2155-2160.

73. Huang, W. On the selection of shape memory alloys for actuators. Mater. Des. 2002, 23, 11-19.

74. Yang, B.; Huang, W.M.; Li, C.; Li, L. Effects of moisture on the thermomechanical properties of a polyurethane shape memory polymer. Polymer 2006, 47, 1348-1356.

75. Tobushi, H.; Hara, H.; Yamada, E.; Hayashi, S. Thermomechanical properties in a thin film of shape memory polymer of polyurethane series. Smart Mater. Struct. 1996, 5, 483-491.

76. Tey, S.J.; Huang, W.M.; Sokolowski, W.M. Influence of long-term storage in cold hibernation on strain recovery and recovery stress of polyurethane shape memory polymer foam. Smart Mater. Struct. 2001, 10, 321-325.

77. Tobushi, H.; Matsui, R.; Hayashi, S.; Shimada, D. The influence of shape-holding conditions on shape recovery of polyurethane-shape memory polymer foams. Smart Mater. Struct. 2004, 13, 881-887.

78. Tobushi, H.; Hayashi, S.; Hoshio, K.; Ejiri, Y. Shape recovery and irrecoverable strain control in polyurethane shape-memory polymer. Sci. Technol. Adv. Mater. 2008, 9, doi:10.1088/14686996/9/1/015009.

79. Muller, W.W.; Pretsch, T. Hydrolytic aging of crystallizable shape memory poly(ester urethane): Effects on the thermo-mechanical properties and visco-elastic modeling. Eur. Polym. J. 2010, 46, $1745-1758$.

80. Pretsch, T.; Muller, W.W. Shape memory poly(ester urethane) with improved hydrolytic stability. Polym. Degrad. Stab. 2010, 95, 880-888. 
81. Castro, F.; Westbrook, K.K.; Hermiller, J.; Ahn, D.U.; Ding, Y.F.; Qi, H.J. Time and temperature dependent recovery of epoxy-based shape memory polymers. J. Eng. Mater. Technol. 2011, 133, 021025:1-021025:9.

82. Bhattacharyya, A.; Tobushi, H. Analysis of the isothermal mechanical response of a shape memory polymer rheological model. Polym. Eng. Sci. 2000, 40, 2498-2510.

83. Ge, Q.; Luo, X.F.; Rodriguez, E.D.; Zhang, X.; Mather, P.T.; Dunn, M.L.; Qi, H.J. Thermomechanical behavior of shape memory elastomeric composites. J. Mech. Phys. Solids 2012, 60, 67-83.

84. Azra, C.; Plummer, C.J.G.; Manson, J.A.E. Isothermal recovery rates in shape memory polyurethanes. Smart Mater. Struct. 2011, 20, doi:10.1088/0964-1726/20/8/082002.

85. Choi, J.; Ortega, A.M.; Xiao, R.; Yakacki, C.M.; Nguyen, T.D. Effect of physical aging on the shape-memory behavior of amorphous networks. Polymer 2012, 53, 2453-2464.

86. Ortega, A.M.; Yakacki, C.M.; Dixon, S.A.; Likos, R.; Greenberg, A.R.; Gall, K. Effect of crosslinking and long-term storage on the shape-memory behavior of (meth)acrylate-based shape-memory polymers. Soft Matter 2012, 8, 7381-7392.

87. Gunes, I.S.; Jimenez, G.A.; Jana, S.C. Carbonaceous fillers for shape memory actuation of polyurethane composites by resistive heating. Carbon 2009, 47, 981-997.

88. Ding, Z. Shape Memory Hybrids: Mechanism and Design for Tailored Properties. Ph.D. Thesis, Nanyang Technological University, Singapore, 2011.

89. Wang, C.C.; Huang, W.M.; Ding, Z.; Zhao, Y.; Purnawali, H.; Zheng, L.X.; Fan, H.; He, C.B. Rubber-like shape memory polymeric materials with repeatable thermal-assisted healing function. Smart Mater. Struct. 2012, 21, doi:10.1088/0964-1726/21/11/115010.

90. Weiss, R.A.; Izzo, E.; Mandelbaum, S. New design of shape memory polymers: Mixtures of an elastomeric ionomer and low molar mass fatty acids and their salts. Macromolecules 2008, 41 , 2978-2980.

91. Shi, Y.; Yoonessi, M.; Weiss, R.A. High temperature shape memory polymers. Macromolecules 2013, 46, 4160-4167.

92. Dong, J.; Weiss, R.A. Effect of crosslinking on shape-memory behavior of zinc stearate/ionomer compounds. Macromol. Chem. Phys. 2013, 214, 1238-1246.

93. Koerner, H.; Strong, R.J.; Smith, M.L.; Wang, D.H.; Tan, L.S.; Lee, K.M.; White, T.J.; Vaia, R.A. Polymer design for high temperature shape memory: Low crosslink density polyimides. Polymer 2013, 54, 391-402.

94. Lee, K.M.; Wang, D.H.; Koerner, H.; Vaia, R.A.; Tan, L.S.; White, T.J. Photomechanical response of pre-strained azobenzene-functionalized polyimide materials. Macromol. Chem. Phys. 2013, 214, 1189-1194.

95. Ahn, S.; Kasi, R.M. Exploiting microphase-separated morphologies of side-chain liquid crystalline polymer networks for triple shape memory properties. Adv. Funct. Mater. 2013, 21, 4543-4549.

96. Zhang, D.W.; Petersen, K.M.; Grunlan, M.A. Inorganic-organic shape memory polymer (SMP) foams with highly tunable properties. ACS Appl. Mater. Interfaces 2013, 5, 186-191.

97. Huang, W.M.; Yang, B.; Li, C.; Chan, Y.S.; Li, A. Response to comment on water-driven programmable polyurethane shape memory polymer: Demonstration and mechanism. Appl. Phys. Lett. 2010, 97, 056102. 
98. Jung, Y.C.; So, H.H.; Cho, J.W. Water-responsive shape memory polyurethane block copolymer modified with polyhedral oligometric silsesquioxane. J. Macromol. Sci. B 2006, 45, 1189-1189.

99. Yang, B. Influence of Moisture in Polyurethane Shape Memory Polymers and their Electrical Conductive Composites. Ph.D. Thesis, Nanyang Technological University, Singapore, 2007.

100. Yang, B.; Huang, W.M.; Li, C.; Lee, C.M.; Li, L. On the enects of moisture in a polyurethane shape memory polymer. Smart Mater. Struct. 2004, 13, 191-195.

101. Huang, W.M.; Yang, B.; Li, A.; Li, C.; Chan, Y.S. Water-driven programmable polyurethane shape memory polymer: Demonstration and mechanism. Appl. Phys. Lett. 2005, 86, 114105:1-114105:3.

102. Wang, C.C.; Zhao, Y.; Purnawali, H.; Huang, W.M.; Sun, L. Chemically induced morphing in polyurethane shape memory polymer micro fibers/springs. React. Funct. Polym. 2012, 72, 757-764.

103. Zhao, Y.; Wang, C.C.; Huang, W.M.; Purnawali, H.; An, L. Formation of micro protrusive lens arrays atop poly(methyl methacrylate). Opt. Express 2011, 19, 26000-26005.

104. Huang, W.M.; Song, C.L.; Fu, Y.Q.; Wang, C.C.; Zhao, Y.; Purnawali, H.; Lu, H.B.; Tang, C. Shaping tissue with shape memory materials. Adv. Drug Deliv. Rev. 2013, 65, 515-535.

105. Zhao, Y.; Wang, C.C.; Huang, W.M.; Purnawali, H. Buckling of poly(methyl methacrylate) in stimulus-responsive shape recovery. Appl. Phys. Lett. 2011, 99, 131911:1-131911:3.

106. DiOrio, A.M.; Luo, X.F.; Lee, K.M.; Mather, P.T. A functionally graded shape memory polymer. Soft Matter 2011, 7, 68-74.

107. Bellin, I.; Kelch, S.; Langer, R.; Lendlein, A. Polymeric triple-shape materials. Proc. Natl. Acad. Sci. USA 2006, 103, 18043-18047.

108. Xie, T. Tunable polymer multi-shape memory effect. Nature 2010, 464, 267-270.

109. Sun, L.; Huang, W.M. Mechanisms of the multi-shape memory effect and temperature memory effect in shape memory polymers. Soft Matter 2010, 6, 4403-4406.

110. Bae, C.Y.; Park, J.H.; Kim, E.Y.; Kang, Y.S.; Kim, B.K. Organic-inorganic nanocomposite bilayers with triple shape memory effect. J. Mater. Chem. 2011, 21, 11288-11295.

111. Bothe, M.; Mya, K.Y.; Lin, E.M.J.; Yeo, C.C.; Lu, X.H.; He, C.B.; Pretsch, T. Triple-shape properties of star-shaped poss-polycaprolactone polyurethane networks. Soft Matter 2012, 8, 965-972.

112. Kumar, U.N.; Kratz, K.; Behl, M.; Lendlein, A. Shape-memory properites of magnetically active triple-shape nanocomposities based on a grafted polymer network with two crystallizable switching segments. Express Polym. Lett. 2012, 6, 26-40.

113. Zotzmann, J.; Behl, M.; Lendlein, A. The influence of programming conditions on the triple-shape effect of copolymer networks with poly $(\omega$-pentadecalactone) and poly( $\varepsilon$-caprolactone) as switching segments. Macromol. Symp. 2011, 309/310, 147-153.

114. Li, J.J.; Xie, T. Significant impact of thermo-mechanical conditions on polymer triple-shape memory effect. Macromolecules 2011, 44, 175-180.

115. Chen, S.J.; Hu, J.L.; Yuen, C.W.M.; Chan, L.K.; Zhuo, H.T. Triple shape memory effect in multiple crystalline polyurethanes. Polym. Adv. Technol. 2010, 21, 377-380.

116. Kumar, U.N.; Kratz, K.; Wagermaier, W.; Behl, M.; Lendlein, A. Non-contact actuation of triple-shape effect in multiphase polymer network nanocomposites in alternating magnetic field. J. Mater. Chem. 2010, 20, 3404-3415. 
117. Cuevas, J.M.; Rubio, R.; German, L.; Laza, J.M.; Vilas, J.L.; Rodriguez, M.; Leon, L.M. Triple-shape memory effect of covalently crosslinked polyalkenamer based semicrystalline polymer blends. Soft Matter 2012, 8, 4928-4935.

118. Li, J.; Liu, T.; Xia, S.; Pan, Y.; Zheng, Z.H.; Ding, X.B.; Peng, Y.X. A versatile approach to achieve quintuple-shape memory effect by semi-interpenetrating polymer networks containing broadened glass transition and crystalline segments. J. Mater. Chem. 2011, 21, 12213-12217.

119. Behl, M.; Bellin, I.; Kelch, S.; Wagermaier, W.; Lendlein, A. One-step process for creating triple-shape capability of ab polymer networks. Adv. Funct. Mater. 2009, 19, 102-108.

120. Airoldi, G.; Besseghini, S.; Riva, G. Micromemory effects in shape memory alloys. Il Nuovo Cimento D 1993, 15, 365-374.

121. Riva, G.; Airoldi, G.; Besseghini, S. The step-wise martensite to austenite reversible transformation. Meccanica 1995, 30, 495-503.

122. Sun, L.; Huang, W.M.; Cheah, J.Y. The temperature memory effect and the influence of thermo-mechanical cycling in shape memory alloys. Smart Mater. Struct. 2010, 19, doi:10.1088/0964-1726/19/5/055005.

123. Liu, N.; Huang, W.M. Comments on incomplete transformation induced multiple-step transformation in tini shape memory alloys. Scr. Mater. 2006, 55, 493-495.

124. Miaudet, P.; Derré, A.; Maugey, M.; Zakri, C.; Piccione, P.M.; Inoubli, R.; Poulin, P. Shape and temperature memory of nanocomposites with broadened glass transition. Science 2007, 318, 1294-1296.

125. Kratz, K.; Voigt, U.; Lendlein, A. Temperature-memory effect of copolyesterurethanes and their application potential in minimally invasive medical technologies. Adv. Funct. Mater. 2012, 22, 3057-3065.

126. Sun, L.; Huang, W.M.; Wang, C.C.; Zhao, Y.; Ding, Z.; Purnawali, H. Optimization of the shape memory effect in shape memory polymers. J. Polym. Sci. A Polym. Chem. 2011, 49, 3574-3581.

127. Lee, K.M.; Bunning, T.J.; White, T.J. Autonomous, hands-free shape memory in glassy, liquid crystalline polymer networks. Adv. Mater. 2012, 24, 2839-2843.

128. Hong, S.J.; Yu, W.R.; Youk, J.H. Two-way shape memory behavior of shape memory polyurethanes with a bias load. Smart Mater. Struct. 2010, 19, doi:10.1088/0964-1726/19/3/035022.

129. Pandini, S.; Passera, S.; Messori, M.; Paderni, K.; Toselli, M.; Gianoncelli, A.; Bontempi, E.; Ricco, T. Two-way reversible shape memory behaviour of crosslinked poly(e-caprolactone). Polymer 2012, 53, 1915-1924.

130. Martin, B.; Thorsten, P. Two-way shape changes of a shape-memory poly(ester urethane). Macromol. Chem. Phys. 2012, 213, 2378-2385.

131. Du, H.Y.; Zhang, J.H. Solvent induced shape recovery of shape memory polymer based on chemically cross-linked poly(vinyl alcohol). Soft Matter 2010, 6, 3370-3376.

132. Lu, H.B.; Liu, Y.J.; Gou, J.H.; Leng, J.S.; Du, S.Y. Surface coating of multi-walled carbon nanotube nanopaper on shape-memory polymer for multifunctionalization. Compos. Sci. Technol. 2011, 71, 1427-1434.

133. Sauter, T.; Lutzow, K.; Schossig, M.; Kosmella, H.; Weigel, T.; Kratz, K.; Lendlein, A. Shape-memory properties of polyetherurethane foams prepared by thermally induced phase separation. Adv. Eng. Mater. 2012, 14, 818-824. 
134. Ahmad, M.; Luo, J.K.; Purnawali, H.; Huang, W.M.; King, P.J.; Chalker, P.R.; Mireftab, M.; Geng, J. Making shape memory polymers reprocessable and reusable by a simple chemical method. J. Mater. Chem. 2012, 22, 8192-8194.

135. Zhang, Y.M.; Wang, Q.H.; Wang, C.; Wang, T.M. High-strain shape memory polymer networks crosslinked by $\mathrm{SiO}_{2}$. J. Mater. Chem. 2011, 21, 9073-9078.

136. Schoener, C.A.; Weyand, C.B.; Murthy, R.; Grunlan, M.A. Shape memory polymers with silicon-containing segments. J. Mater. Chem. 2010, 20, 1787-1793.

137. Gunes, I.S.; Perez-Bolivar, C.; Cao, F.N.; Jimenez, G.A.; Anzenbacher, P.; Jana, S.C. Analysis of non-covalent interactions between the nanoparticulate fillers and the matrix polymer as applied to shape memory performance. J. Mater. Chem. 2010, 20, 3467-3474.

138. Rousseau, I.A.; Xie, T. Shape memory epoxy: Composition, structure, properties and shape memory performances. J. Mater. Chem. 2010, 20, 3431-3441.

139. Xu, B.; Fu, Y.Q.; Ahmad, M.; Luo, J.K.; Huang, W.M.; Kraft, A.; Reuben, R.; Pei, Y.T.; Chen, Z.G.; de Hosson, J.T.M. Thermo-mechanical properties of polystyrene-based shape memory nanocomposites. J. Mater. Chem. 2010, 20, 3442-3448.

140. Jang, M.K.; Hartwig, A.; Kim, B.K. Shape memory polyurethanes cross-linked by surface modified silica particles. J. Mater. Chem. 2009, 19, 1166-1172.

141. Kunzelman, J.; Chung, T.; Mather, P.T.; Weder, C. Shape memory polymers with built-in threshold temperature sensors. J. Mater. Chem. 2008, 18, 1082-1086.

142. Ionov, L. Soft microorigami: Self-folding polymer films. Soft Matter 2011, 7, 6786-6791.

143. Xie, T.; Xiao, X.C.; Li, J.J.; Wang, R.M. Encoding localized strain history through wrinkle based structural colors. Adv. Mater. 2010, 22, 4390-4394.

144. Li, J.J.; An, Y.H.; Huang, R.; Jiang, H.Q.; Xie, T. Unique aspects of a shape memory polymer as the substrate for surface wrinkling. ACS Appl. Mater. Interfaces 2012, 4, 598-603.

145. Zhao, Y.; Huang, W.M.; Fu, Y.Q. Formation of micro/nano-scale wrinkling patterns atop shape memory polymers. J. Micromech. Microeng. 2011, 21, doi:10.1088/0960-1317/21/6/067007.

146. Chaunier, L.; Lourdin, D. The shape memory of starch. Starch-Starke 2009, 61, 116-118.

147. Luo, X.F.; Mather, P.T. Preparation and characterization of shape memory elastomeric composites. Macromolecules 2009, 42, 7251-7253.

148. Pan, G.H.; Huang, W.M.; Ng, Z.C.; Liu, N.; Phee, S.J. The glass transition temperature of polyurethane shape memory polymer reinforced with treated/non-treated attapulgite (playgorskite) clay in dry and wet conditions. Smart Mater. Struct. 2008, 17, doi:10.1088/0964-1726/17/4/045007.

149. Xu, B.; Huang, W.M.; Pei, Y.T.; Chen, Z.G.; Kraft, A.; Reuben, R.; de Hosson, J.T.M.; Fu, Y.Q. Mechanical properties of attapulgite clay reinforced polyurethane shape-memory nanocomposites. Eur. Polym. J. 2009, 45, 1904-1911.

150. Yakacki, C.M.; Nguyen, T.D.; Likos, R.; Lamell, R.; Guigou, D.; Gall, K. Impact of shape-memory programming on mechanically-driven recovery in polymers. Polymer 2011, 52, 4947-4954.

(C) 2013 by the authors; licensee MDPI, Basel, Switzerland. This article is an open access article distributed under the terms and conditions of the Creative Commons Attribution license (http://creativecommons.org/licenses/by/3.0/). 